\title{
Comparison of the Mechanism of Toxicity of Zinc Oxide and Cerium Oxide Nanoparticles Based on Dissolution and Oxidative Stress Properties
}

\author{
Tian Xia ${ }^{1}{ }^{,}$, Michael Kovochich ${ }^{1,{ }^{*}}$, Monty Liong ${ }^{2}$, Lutz Mädler ${ }^{3,8}$, Benjamin Gilbert ${ }^{4}$, Haibin \\ $\mathrm{Shi}^{5}$, Joanne I. Yeh ${ }^{5,6}$, Jeffrey I. Zink ${ }^{2,7}$, and Andre E. Nel ${ }^{1,7,8, \$}$ \\ ${ }^{1}$ Division of NanoMedicine, Department of Medicine, University of California, Los Angeles, CA \\ 90095 \\ ${ }^{2}$ Department of Chemistry \& Biochemistry, University of California, Los Angeles, CA 90095 \\ ${ }^{3}$ Foundation Institute of Materials Science, Division of Process \& Chemical Engineering, \\ Department of Production Engineering, University of Bremen, Germany \\ ${ }^{4}$ Earth Science Division, Lawrence Berkeley National Laboratory, Berkeley, CA 94720 \\ ${ }^{5}$ Department of Structural Biology, University of Pittsburgh Medical School, Pittsburgh, PA 15260 \\ ${ }^{6}$ Department of Bioengineering, University of Pittsburgh Medical School, Pittsburgh, PA 15260 \\ ${ }^{7}$ The Southern California Particle Center, University of California, Los Angeles, CA 90095 \\ ${ }^{8}$ California NanoSystems Institute, University of California, Los Angeles, CA 90095
}

\begin{abstract}
Nanomaterials (NM) exhibit novel physicochemical properties that determine their interaction with biological substrates and processes. Three metal oxides nanoparticles that are currently being produced in high tonnage, $\mathrm{TiO}_{2}, \mathrm{ZnO}$ and $\mathrm{CeO}_{2}$, were synthesized by flame spray pyrolysis process and compared in a mechanistic study to elucidate the physicochemical characteristics that determine cellular uptake, subcellular localization, and toxic effects based on a test paradigm that was originally developed for oxidative stress and cytotoxicity in RAW 264.7 and BEAS-2B cell lines. $\mathrm{ZnO}$ induced toxicity in both cells, leading to the generation of reactive oxygen species (ROS), oxidant injury, excitation of inflammation and cell death. Using ICP-MS and fluorescentlabeled $\mathrm{ZnO}$, it is found that $\mathrm{ZnO}$ dissolution could happen in culture medium and endosomes. Non-dissolved $\mathrm{ZnO}$ nanoparticles enter caveolae in BEAS-2B, but enter lysosomes in RAW 264.7 cells in which smaller particle remnants dissolve. In contrast, fluorescent-labeled $\mathrm{CeO}_{2}$ nanoparticles were taken up intact into caveolin-1 and LAMP-1 positive endosomal compartments, respectively, in BEAS-2B and RAW 264.7 cells, without inflammation or cytotoxicity. Instead, $\mathrm{CeO}_{2}$ suppressed $\mathrm{ROS}$ production and induced cellular resistance to an exogenous source of oxidative stress. Fluorescent-labeled $\mathrm{TiO}_{2}$ was processed by the same uptake pathways as $\mathrm{CeO}_{2}$ but did not elicit any adverse or protective effects. These results demonstrate that metal oxide nanoparticles induce a range of biological responses that vary from cytotoxic to
\end{abstract}

\footnotetext{
${ }^{\$}$ Corresponding Author: Andre Nel, M.D., Department of Medicine, Division of NanoMedicine, UCLA School of Medicine, 52-175 CHS, 10833 Le Conte Ave, Los Angeles, CA 90095-1680. Tel: (310) 825-6620, Fax: (310) 206-8107 anel@ mednet.ucla.edu. *Contributed equally to this work

Supporting Information Available: Separation of non-dissolved ZnO nanoparticles, calibration of CNT-NADH peroxidase (Npx)bioelectrode, relative mRNA levels in cells, TEM of cells, surface modification and fluorescent labeling of metal oxides, Confocal microscopy to study the cellular distribution of $\mathrm{Zn}^{2+}$. This material is available free of charge via the Internet at http://pubs.acs.org.
} 
cytoprotective and can only be properly understood by using a tiered test strategy such as we developed for oxidative stress and adapted to study other aspects of nanoparticle toxicity.

\section{Keywords}

Nanotoxicology; Nanoparticle; Reactive oxygen species; Oxidative stress; Dissolution; Nano-bio interface

Ensuring the safety of engineered nanomaterials (NM) is of great importance to the nanotechnology industry that is continuing its march towards a $\$ 1$ trillion enterprise by $2015 .{ }^{1}$ While it is likely that most engineered NM are safe, the uncertainty about the novel properties of these materials and how that may relate to nanoscale operations at the biological level has generated considerable concern and could impact the implementation and acceptance of this new technology in society. ${ }^{1}$ Evaluation of NM safety has to consider the interfacial properties of these materials, including their interaction with proteins, DNA, lipids, membranes, organelles, cells, tissues, and biological fluids. While the traditional toxicological approach to chemical testing involves animal studies as the primary means of hazard assessment, this strategy is costly and labor intensive. As a result, only a few hundred of the 50,000 or so industrial chemicals in the US have undergone toxicity testing and therefore leaves us exposed to new toxicological scares on a continuous basis. While admittedly it is impossible to perform risk assessment and management without in vivo toxicological data, it is becoming clear that animal testing may not provide the base test method when confronted with thousands of new chemicals and nanomaterials.

Consequently, we have proposed the development of predictive in vitro toxicological screening to rank NM for priority in vivo testing. ${ }^{1}$ The National Research Council of the US National Academy of Sciences (NAS) also opined that toxicological testing in the 21stcentury should undergo a paradigm shift from a predominant observational science performed in whole animals to a target-specific and predictive in vitro science that utilizes mechanisms of injury and toxicological pathways to guide the judicious use of in vivo studies. ${ }^{2,3}$ This opinion is compatible with the increasing public demand to reduce or even eliminate animal use for toxicological screening purposes. Our long-term goal is to establish predictive screening models that can be used for NM priority testing in vivo.

Biological systems generally are able to integrate multiple pathways of toxicity into a limited number of pathological outcomes, including inflammation, apoptosis, necrosis, fibrosis, hypertrophy, metaplasia and carcinogenesis. ${ }^{1}$ To date, the best predictions of ambient and mineral dust particle toxicity have been a small particle size and a large reactive surface area that can lead to toxicological injury through the production of reactive oxygen species (ROS) and oxidative stress. ${ }^{1,4-8}$ While admittedly these "inadvertently" generated nanoparticles differ from engineered NM, it is noteworthy that many of the toxicological studies on the latter class of materials involve ROS production and the induction of oxidative stress. ${ }^{1}$ Thus, the theme of particle-induced ROS production and oxidative injury has become an established paradigm for NP toxicity. ${ }^{1,9,10}$ To facilitate the implementation of this screening procedure for NP toxicity, we have formulated the hierarchical oxidative stress model to provide us with an interlinked range of cellular responses to study NM oxidant injury. At the lowest level of oxidative stress (Tier 1), the induction of antioxidant and detoxification enzymes is mediated by the transcription factor, Nrf2, which regulates the expression of the antioxidant response element (ARE) in the promoter of phase 2 genes. ${ }^{11,12}$ At higher levels of oxidative stress (Tier 2), this protective response transitions to proinflammatory responses based on the ability of ROS to induce redox sensitive signaling pathways such as the MAP kinases and NF- $\kappa \mathrm{B}$ cascades. ${ }^{12}$ At the highest level of oxidative stress (Tier 3), a perturbation of inner membrane electron transfer and the open/closed status 
of the mitochondrial permeability transition pore (PTP) can trigger cellular apoptosis and cytotoxicity, also known as toxic oxidative stress. Utility of this screening platform has allowed us to compare batches of NP as well as the functionalization of a single particle type to discern between potentially hazardous or potentially safe NP. ${ }^{7}$ We have also shown that the hierarchical stress paradigm can be applied to the study and prediction of the adverse health effects of ambient ultrafines in animal disease models. ${ }^{13,14}$ For instance, we have demonstrated that the higher oxidant potential of ambient ultrafine particles (aerodynamic diameter $<100 \mathrm{~nm}$ ) is associated with increased vascular inflammation (atherosclerotic plaques) in apoE knockout mice compared to larger (PM $2.5 \mu \mathrm{m}$ ) ambient particles. ${ }^{13}$ Moreover, the in vivo vascular injury could be mechanistically linked to synergistic oxidative stress responses that are derived from redox-active particle compounds as well as oxidized LDL components; this synergy generates a genomic footprint that mimics the hierarchical oxidative stress paradigm. ${ }^{14}$ All considered, these data suggest that the use of the hierarchical oxidative stress paradigm for air pollution and mineral dust toxicity is indeed a predictive scientific platform that can be used to assess particle hazard. ${ }^{15}$

NP injury can also proceed by non-oxidant paradigms. One example is the ability of NP to organize around them a protein corona that depends on particle size, curvature, shape, and surface characteristics such as charge, functionalized groups and free energy. ${ }^{16}$ As a consequence of this binding, some particles could generate adverse biological outcomes through protein unfolding, fibrillation, thiol crosslinking, and loss of enzymatic activity. ${ }^{17-19}$ Another paradigm of NP toxicity is the release of toxic ions when the thermodynamic properties of a material (including surface free energy) favor particle dissolution in a suspending medium or biological environment. ${ }^{20} \mathrm{An}$ example is $\mathrm{ZnO}$ nanoparticles that could dissolve under aqueous conditions to form hydrated $\mathrm{Zn}^{2+}$ cations. ${ }^{21}$ This dissolution is increased under acidic conditions as well as the presence of biological components such as amino acids and peptides. ${ }^{21,22}$ Although it is known that $\mathrm{ZnO}$ particles are toxic to mammalian cells in vitro and the human lung in vivo, the mechanism of toxicity is improperly understood, including to what extent sequential nano-bio interfaces (e.g., in the suspending medium or intracellularly) contribute to dissolution and toxicity. Ultrafine $\mathrm{ZnO}$ particles are capable of reaching the alveoli and cause pulmonary inflammation and symptomatic responses in the lung through increased TNFa, IL-6, and IL-8 production. ${ }^{23-25}$ This manifests as metal fume fever in welders. ${ }^{26,27}$ Although $\mathrm{ZnO}$ dissolution can induce cytotoxicity and apoptosis in mammalian cells, ${ }^{28,29}$ few of these studies have linked this to a mechanistic paradigm such as oxidant injury. Finally, it is important to consider that some NP may generate bio-protective effects against oxidant injury. ${ }^{30}$ This could be particularly relevant to cerium oxide. ${ }^{30-32}$

The three metal oxides that were compared in this study are relevant NM types that are being produced in high tonnage and are in widespread use in a number of consumer products. $\mathrm{TiO}_{2}$ is a semiconductor that it is widely used in catalysts and pigments. This material responds to UV exposure with the generation electron-hole pairs that can lead to biological injury through oxygen radical production or electron capture. However, we can not perform UV exposure in this study because of the potential toxicity in tissue culture cells. $\mathrm{CeO}_{2}$ is widely used in catalysts, fuel additives and polishing agents. Interesting data have been presented suggesting that this material can exert antioxidant effects in tissue culture cells. ${ }^{30} \mathrm{ZnO}$ particles are widely used as polymer fillers and UV absorbers. While $\mathrm{ZnO}$ dissolution has been shown to play a role in the acute or chronic toxicity of aquatic organisms, very little is understood about its mechanism(s) of toxicity in mammalian cells.

We compared the effects of $\mathrm{ZnO}$ and $\mathrm{CeO}_{2} \mathrm{NP}$ in macrophage and epithelial cells according to the oxidant injury paradigm. $\mathrm{TiO}_{2}$ was included as a metal oxide that does not cause toxicological injury to mammalian cells under dark conditions. ${ }^{7}$ Our data show differential 
toxic effects with $\mathrm{ZnO}$ exhibiting major toxicity based on a mechanism of particle dissolution and $\mathrm{Zn}^{2+}$ release that engages the oxidant injury paradigm through differential cellular uptake and processing in macrophages and epithelial cells. By contrast, internalized $\mathrm{CeO}_{2}$ particles exerted a cytoprotective effect due to its antioxidant properties. $\mathrm{TiO}_{2}$ was inert. These data provide further evidence for the utility of the hierarchical oxidative stress paradigm as a screening tool that can be applied to NP that undergo dissolution or that exert antioxidant effects.

\section{Results}

\section{Synthesis and physicochemical characterization of metal oxide nanoparticles}

We used flame spray pyrolysis (FSP) to synthesize $\mathrm{TiO}_{2}, \mathrm{CeO}_{2}$, and $\mathrm{ZnO} \mathrm{NP}^{33-37}$ This process is used by industry and yields NP with highly reproducible primary particle size, crystallinity and lack of microporosity. ${ }^{35-37}$ These particles were characterized under dry as well as aqueous conditions. $\mathrm{TiO}_{2}, \mathrm{ZnO}$ and $\mathrm{CeO}_{2}$ are synthesized as single crystalline particles with primary sizes of 11,13 and $8 \mathrm{~nm}$, respectively, as determined by BET and XRD (Table 1). The primary particle sizes were also confirmed by TEM analysis (Fig. 1). The TEM micrographs demonstrate the particle shapes as well as their tendency to aggregate under dry conditions (Fig. 1). Interestingly, the particle size distribution in water (Table 1) changes considerably upon suspension in complete tissue culture medium, which contains salts, serum proteins and growth factors that could play a role in particle dispersion and dissolution (Table 1) ${ }^{38}$ Particularly noteworthy is the shrinkage of $\mathrm{ZnO}$ aggregate particles size from 413 to $36 \mathrm{~nm}$ (Table 1).

We studied the dissolution of $\mathrm{ZnO} \mathrm{NP}$ in water and cell-free culture media in order to estimate the role that dissolved $\mathrm{Zn}$ ions may contribute to cellular toxicity. Zinc concentration was measured using ICP-MS. By equilibrating excess commercial $\mathrm{ZnO}$ nanopowder (Sigma) with these liquids for 4 days at $22^{\circ} \mathrm{C}$, we estimated the maximum total dissolved zinc concentrations that could be attained in the cytotoxicity experiments to be $190 \mu \mathrm{M}$ in BEGM (BEAS-2B) and $225 \mu \mathrm{M}$ in complete DMEM (RAW264.7). The high solubility of $\mathrm{ZnO}$ nanopowder in the cell culture media indicates the formation of aqueous complexes of zinc ions with organic or inorganic constituents of these complex media. Because it is not known whether the solutions had reached thermodynamic equilibrium with respect to aqueous complex formation and because we did not test for the formation of alternative $\mathrm{Zn}$-bearing solid phases such as $\mathrm{Zn}(\mathrm{OH})_{2}$ these measurements may not represent true saturation concentrations. The data place limits on the total amount of dissolved $\mathrm{Zn}$ that may be produced by ZnO NP dissolution in cell culture medium.

We also investigated whether the rate of $\mathrm{ZnO}$ NP dissolution in the culture media was fast enough for significant quantities of dissolved $\mathrm{Zn}$ to be generated when $\mathrm{ZnO}$ particles were added to the cell cultures. Tests of the separation procedure at higher $\mathrm{ZnO}$ concentrations (Fig. S1) showed it to be effective for removing non-dissolved ZnO NP from BEGM. However, centrifugation for up to 20 minutes could not completely remove excess $\mathrm{ZnO}$ from complete DMEM, as the apparent dissolved Zn concentration consistently exceeded the measured maximum concentration measured with larger particles. This is likely a result both of the high viscosity of the DMEM solution and the breakup of aggregates into smaller fragments that settle more slowly during centrifugation. Nevertheless, the high $\mathrm{ZnO}$ solubility in this solution and the observed breakup of the initial aggregates indicate that dissolution is likely also rapid on the timescale of the cell exposure experiments. The ready dissolution of $\mathrm{ZnO} \mathrm{NP}$ in the aqueous tissue culture media can be expected to reach $>80 \%$ of the maximum total dissolved [ $\mathrm{Zn}]$ within three hours. Thus, when less than maximum [ZnO] is used we expect that the cell cultures to be mainly exposed to aqueous $\mathrm{Zn}$ ions but when 
particle concentrations are used that exceed $\mathrm{ZnO}$ solubility cells will be exposed to nondissolved NP.

\section{Differential toxic effects of metal oxide NP in RAW 264.7 and BEAS-2B cells}

RAW 264.7 was chosen as representative of a phagocytic cell line while BEAS-2B cells represent transformed human bronchial epithelial cells. Both cell lines have been used extensively for NP and ambient UFP toxicity studies, including assessment of cellular uptake routes and study of cellular stress responses ${ }^{39,40}$ For instance, while toxic cationic polystyrene (PS) nanospheres enter a LAMP 1-positive acidifying lysosomal compartment in RAW 264.7 cells, BEAS-2B cells endocytose albumin-coated gold particles and cationic PS nanospheres via caveolae. ${ }^{40}$ Toxicity testing by following propidium iodide (PI) uptake in cells revealed that $\mathrm{ZnO}$ but not $\mathrm{TiO}_{2}$ or $\mathrm{CeO}_{2} \mathrm{NP}$ could induce cytotoxicity in RAW 264.7 and BEAS-2B cells (Fig. 2A). Differences in their toxicity profile were confirmed by the MTS assay (Fig. S2) that was used for the performance of time- (Fig. S2A) and doseresponse kinetics (Fig. S2B).

In order to determine whether the $\mathrm{ZnO}$ particle effect differs from the toxicity of equimolar amounts of ionized $\mathrm{Zn}^{2+}$, RAW 264.7 and BEAS-2B cells were treated with $\mathrm{ZnO}$ NP as well as a $\mathrm{ZnSO}_{4}$ solution. Fig. 2B shows that fully dissolved $\mathrm{ZnSO}_{4}$ induced a significant higher rate of cell death than an equivalent amount of $\mathrm{Zn}$ in the form of $\mathrm{ZnO}$. This is compatible with the $\mathrm{ZnO}$ dissolution data discussed above in which we estimated that the maximum aqueous [Zn] of $190 \mu \mathrm{M}$ (BEGM) and $225 \mu \mathrm{M}$ (CDMEM) is significantly lower than what can be attained with the sulfate salt. However, even when $\mathrm{ZnSO}_{4}$ and $\mathrm{ZnO}$ are added at concentrations lower than these levels, so that only dissolved $\mathrm{Zn}^{2+}$ is expected to be present, $\mathrm{ZnSO}_{4}$ is still more toxic than $\mathrm{ZnO}$ (Fig. 2B). These findings indicate that the mechanism or rate of aqueous $\mathrm{Zn}$ introduction into the cellular environment can have a significant effect on the toxicity of the soluble species. Since at higher [ZnO] only partial NP dissolution is possible, the more rapid rise in the rate of cell death that is observed must be attributed to the presence and uptake of solid $\mathrm{ZnO} \mathrm{NP}$.

\section{Assessment of ROS generation under abiotic and biotic conditions}

We have previously shown that ROS generation and the induction of oxidative stress is a major toxicological paradigm for ambient and engineered NP. ${ }^{7}$ ROS generation can originate at the particle surface as a result of the material semiconductor or electronic properties as well as the capability of some materials to perturb electronic transfer processes in the cell such as in the mitochondrial inner membrane. Thus, while the toxicity of ambient ultrafine and quartz particles is dependent on particle composition or adsorbed chemicals that generate ROS abiotically, cationic PS nanospheres are electronically inert but can generate ROS through mitochondrial damage. ${ }^{7}$ We have previously shown that spontaneous ROS production by NP can be assessed under abiotic conditions with a carbon nanotube (CNT)-NADH peroxidase (Npx)-bioelectrode array. ${ }^{7}$ This nanobiosensor platform exploits the efficiency and specificity of $\mathrm{Npx}$ to detect $\mathrm{H}_{2} \mathrm{O}_{2}$ production when a particle suspension is added to the electrode. ${ }^{7}$ Thus, the amplitude of the deflection during recording of the cyclic voltammogram closely reflects the $\mathrm{H}_{2} \mathrm{O}_{2}$ concentration in the solution; the change in the $\left[\mathrm{H}_{2} \mathrm{O}_{2}\right]$ can be calculated by the addition of standardized amounts of $\mathrm{H}_{2} \mathrm{O}_{2}$ (Fig. S3). Introduction of NP to this bioelectrode array demonstrates weak $\mathrm{H}_{2} \mathrm{O}_{2}$ generation by $\mathrm{TiO}_{2}$, which is in accordance with the UV photoactivation requirements of this material to generate ROS (Fig. 3A). In contrast, both $\mathrm{CeO}_{2}$ and $\mathrm{ZnO}$ induced sizable $\mathrm{H}_{2} \mathrm{O}_{2}$ production, while cationic PS $\left(\mathrm{NH}_{2}-\mathrm{PS}\right)$ showed a weak deflection that is equivalent to background (Fig. $3 \mathrm{~A})$. 
In order to study cellular ROS generation, dichlorofluorescein acetate (DCF) and MitoSOX Red $^{\mathrm{TM}}$ were used to assess the magnitude and kinetics, respectively, for $\mathrm{H}_{2} \mathrm{O}_{2}$ and $\mathrm{O}_{2}{ }^{-}$ production under biotic conditions. ${ }^{7}$ The data show that while $\mathrm{ZnO}$ induced the production of both radicals in RAW 264.7 cells, $\mathrm{CeO}_{2}$ and $\mathrm{TiO}_{2}$ were weak inducers of DCF fluorescence and incapable of generating $\mathrm{O}_{2}$-production (Fig. 3B). Similar results were seen for MitoSOX Red ${ }^{\mathrm{TM}}$ fluorescence in BEAS-2B cells, while DCF fluorescence was essentially negative (Fig. 3B). Thus, while both $\mathrm{ZnO}$ and $\mathrm{CeO}_{2}$ particles are capable of robust spontaneous ROS generation only the former particle type is capable of biological ROS generation. This suggests differences in the mechanism of biological response generation by these particles. We will demonstrate in a later section that $\mathrm{CeO}_{2}$ exerts an antioxidant effect after cellular uptake.

\section{$\mathrm{ZnO}$ induces Tier 1 oxidative stress responses}

Particle-induced ROS production can lead to a range of biological responses, depending on the relative abundance of ROS production and the type of cellular pathways that are engaged by oxidative stress. ${ }^{1,7,41}$ According to the hierarchical oxidative stress hypothesis, the first tier of oxidative stress includes activation of the antioxidant response element in the promoters of phase II genes by the transcription factor, Nrf2. ${ }^{41-43}$ This leads to the expression of cytoprotective enzymes such as $\mathrm{HO}-1, \mathrm{NAD}(\mathrm{P}) \mathrm{H}$ :quinone oxidoreductase 1 (NQO1), superoxide dismutase, catalase, etc.. ${ }^{7,41-43}$ Only $\mathrm{ZnO}$ could generate robust HO-1 message and protein expression in RAW 264.7 and BEAS-2B cells (Figs. 4A, 5A, respectively). $\mathrm{ZnO}$ could also induce increased $\mathrm{Nrf} 2$ and NQO-1 mRNA expression in these cells (Fig. S4). $\mathrm{TiO}_{2}$ and $\mathrm{CeO}_{2}$ were inert. ${ }^{7}$

\section{ZnO induces Tier 2 oxidative stress responses}

If the Tier 1 protection fails to restore cellular redox equilibrium, escalation of the level of oxidative stress is capable of activating pro-inflammatory signaling pathways such as the Jun kinase (JNK) and NF- $\kappa \mathrm{B}$ cascades. ${ }^{11,12}$ While $\mathrm{ZnO}$ particles could effectively induce JNK activation in RAW 264.7 (Fig. 4B, left panel) and BEAS-2B (Fig. 5B, left panel) cells as determined by phosphopeptide immunoblotting, $\mathrm{TiO}_{2}$ and $\mathrm{CeO}_{2}$ were ineffective. Moreover, JNK activation occurred in parallel with increased TNF- $\alpha$ and IL-8 production in RAW 264.7 and BEAS-2B cells, respectively (Figs. 4B, 5B, right panels).

\section{ZnO induces Tier 3 oxidative stress responses}

Intracellular calcium release is a major oxidative stress response that can lead to mitochondrial perturbation and cell death. ${ }^{7}$ This increase in the $\left[\mathrm{Ca}^{2+}\right]_{\mathrm{i}}$ originates from intracellular storage sites such as the endoplasmic reticulum. ${ }^{44,45} \mathrm{ZnO}$ exposure induced a significant and sustained $\left[\mathrm{Ca}^{2+}\right]_{\mathrm{i}}$ increase in both cell types as determined by Fluo- 4 fluorescence (Figs. $4 \mathrm{C}, 5 \mathrm{C}$ ). Although this rise in $\left[\mathrm{Ca}^{2+}\right]_{\mathrm{i}}$ is countered by mitochondrial sequestration to keep the $\left[\mathrm{Ca}^{2+}\right]_{\mathrm{i}}$ constant, this protection only succeeds if the organellar concentration remains below a safe threshold. When this threshold is exceeded, it is capable of triggering the mitochondrial permeability transition pore (PTP). Large-scale PTP opening leads to a dissipation of the mitochondrial membrane potential $(\Delta \Psi \mathrm{m})$ and the possible release of proapoptotic factors. Assessment of cellular $\Delta \Psi \mathrm{m}$ by JC-1 fluorescence showed that $\mathrm{ZnO}$ could effectively increase the $\%$ cells with a lowered $\triangle \Psi \mathrm{m}$ in RAW 264.7 (Fig. $4 \mathrm{C}$ ) and BEAS-2B cultures (Fig. $5 \mathrm{C}$ ). $\mathrm{CeO}_{2}$ and $\mathrm{TiO}_{2}$ did not affect cellular $\mathrm{Ca}^{2+}$ or the $\Delta \Psi \mathrm{m}$.

\section{$\mathrm{CeO}_{2}$ induces cellular protection against an exogenous source of ROS}

It has previously been suggested that $\mathrm{CeO}_{2}$ exerts cytoprotective and antioxidant effects based on the electronic properties of the material. ${ }^{30-32}$ In order to test this hypothesis, both 
cell types were pretreated with $\mathrm{CeO}_{2}$ before subsequent challenge with a pro-oxidative organic DEP extract; this extract contains a high content of redox cycling organic chemicals that are capable of inducing cellular ROS production and toxic oxidative stress. ${ }^{12,46,47}$ Our results demonstrate that prior $\mathrm{CeO}_{2}$ exposure could interfere in the PI uptake and superoxide production in RAW 264.7 and BEAS-2B cells (Fig. 6). This result was confirmed by using the MTS assay (not shown). No protective effect was seen if the $\mathrm{CeO}_{2} \mathrm{NP}$ were added simultaneous with the oxidant stimulus, suggesting the need for prior cellular processing (not shown).

\section{Electron microscopy and confocal studies show selective cellular processing and impact on cellular ultrastructure}

In addition to functional mitochondrial effects, a number of NP (e.g. UFP, fullerenes and micellar nanocontainers) lead to structural mitochondrial changes. ${ }^{7,48,49}$ Electron microscopy (EM) was used to investigate cellular processing of the metal oxide NP. Although $\mathrm{TiO}_{2}$ and $\mathrm{CeO}_{2}$ particles are internalized by membrane-lined vesicles, this occurred without noticeable structural mitochondrial changes (Figs. S5, S6). By contrast, $\mathrm{ZnO}$ particles could not be visualized but the treated cells did exhibit nuclear fragmentation, appearance of apoptotic bodies (Ap) and mitochondrial disappearance (Figs. S5, S6C).

In order to follow more precisely particle processing in the cell, it was necessary to generate fluorescent-labeled NP. We have previously demonstrated how this can be accomplished using polystyrene nanospheres. ${ }^{40}$ Fluorescent labeling of metal oxide NP was achieved by first grafting the particle surface with aminopropyltriethoxysilane, ${ }^{50,51}$ followed by the addition of the amine-reactive dye fluorescein isothiocyanate (FITC), as illustrated in Fig. S7. Utilizing the fluorescent-labeled metal oxide NP at concentrations of $25 \mu \mathrm{g} / \mathrm{mL}$, it was possible to demonstrate distinct routes of particle uptake and processing in BEAS-2B and RAW 264.7 cells (Figs. 7, 8). While it could be shown that all metal oxides localize in a caveolin-1 positive compartment in BEAS-2B cells (Fig. 7), no fluorescence overlap was observed with the late endosomal (LAMP- $1^{+}$) compartment (not shown). The possibility that the FITC staining profile in Fig. 7A could be due to the release of the label from the particle surface was excluded by the performance of dialysis experiments as well as demonstrating that spiking of the culture medium with FITC molecules alone does not result in a cellular staining profile. Please notice that fewer $\mathrm{ZnO}$ particles were taken up in the cell and yielded smaller fluorescent spots (Fig. 7). This likely represents partial particle dissolution in the medium and in the cells following uptake. Also notice that $\mathrm{ZnO}$ toxicity was associated with clumping of the caveolae in the rounded up BEAS-2B cell (Fig. 7, bottom panel). In contrast to a caveolar uptake route in BEAS-2B cells, the FITC labeled $\mathrm{TiO}_{2}$ and $\mathrm{CeO}_{2}$ nanoparticles associated with the late endosomal (LAMP- $1^{+}$) compartment in RAW 264.7 cells (Fig. 8). RAW 264.7 cells exposed to FITC labeled $\mathrm{ZnO}$ at concentrations exceeding the culture medium solubility limit exhibited lysosomal clumping even though no fluorescent $\mathrm{ZnO}$ particles could be visualized in these cells at all (Fig. 8, bottom panel). We infer that the $\mathrm{ZnO}$ particle remnants taken up by these cells are sequestered in lysosomes in which their acidification leads to rapid dissolution and loss of the fluorescent label.

\section{Use of confocal microscopy to study cellular $\mathrm{Zn}^{2+}$ release by Newport Green DCF}

In order to test whether the toxicity of $\mathrm{ZnO} \mathrm{NP}$ is associated with $\mathrm{Zn}^{2+}$ release in the cell, we performed cellular staining with the $\mathrm{Zn}^{2+}$-specific fluorescent dye, Newport Green DCF. ${ }^{52}$ This dye is insensitive to $\mathrm{Ca}^{2+}$ and $\mathrm{Mg}^{2+}{ }^{22}$ Compared to the diffuse and low intensity staining of untreated RAW 264.7 cells (Fig. 9A upper panel), the $\mathrm{ZnO}$ treated cells showed a generalized increase in Newport Green fluorescence with prominent staining of the cellular region that is also stained by the labeled LAMP-1 antibody (Fig. 9A, lower panel). This resulted in a composite orange fluorescence profile, suggesting that $\mathrm{Zn}^{2+}$ 
derived from the particle remnants concentrate in the lysosomal compartment. The fact that already dissolved $\mathrm{ZnSO}_{4}$ could yield the same staining profile (Fig. S8A) is compatible with the data in Fig. 2 that suggests that dissolved $\mathrm{Zn}^{2+}$ from the cell culture medium contributes significantly to the toxicity possibly by uptake and sequestration in lysosomes.

In BEAS-2B cells, the Newport Green staining overlapped with the caveolin-1 stained compartment in $\mathrm{ZnO}$ treated cells (Fig. 9B, lower panel). This likely represents intracellular dissolution of partially dissolved NP is taken up from the culture medium. While $\mathrm{ZnSO}_{4}$ resulted in a generalized increase in cellular fluorescence, this was diffuse and not confined to the caveolar compartment (Fig. S8B).

\section{Discussion}

This paper shows that three metal oxide NP under study induced different cellular responses depending on particle composition, route of cellular uptake, subcellular localization and engagement of oxidative stress pathways. Thus, while $\mathrm{TiO}_{2}$ was localized in late endosomal and caveolar compartments in RAW 264.7 and BEAS-2B cells, the particles did not elicit cytotoxic effects under dark conditions. In contrast, cerium oxide NP induced a cytoprotective response to cellular challenge with an exogenous stress stimulus, while $\mathrm{ZnO}$ induced an injury response characterized by the production of proinflammatory cytokines (Tier 2) and mitochondrial injury (Tier 3 ). This toxicity was directly related to particle dissolution and release of toxic $\mathrm{Zn}^{2+}$ in the cell culture medium (both cell types) as well as the uptake of the particle remnants by specific endosomal compartments in the cells. Utilizing FITC-labeled $\mathrm{ZnO}$ particles, the uptake in BEAS-2B cells occurs in caveolae. Instead, the toxic $\mathrm{Zn}^{2+}$ accumulated in the lysosomal compartment of RAW 264.7 cells, without any evidence of labeled particles in this compartment. While this represents $\mathrm{Zn}^{2+}$ uptake from the culture medium, it is likely that some contribution come from particle remnants that have shed their FITC label. The $\mathrm{Zn}^{2+}$ accumulation in lysosomes and caveolae was associated with organellar clumping, oxidative cell injury, intracellular $\mathrm{Ca}^{2+}$ release, mitochondrial depolarization, cytokine release, and cytotoxicity. By contrast, $\mathrm{CeO}_{2}$ exhibited no cytotoxic effects in spite of similar endosomal processing as $\mathrm{ZnO}$ and $\mathrm{TiO}_{2}$. Moreover, $\mathrm{CeO}_{2}$ protected both cell types against a secondary oxidative stress stimulus, suggesting that the electronic properties of this material may lead to antioxidant protective effects.

This is the first comprehensive study looking at understanding the role of $\mathrm{ZnO}$ dissolution in the generation of mammalian toxicity and is in good agreement with similar attempts in bacteria and algae. ${ }^{21} \mathrm{NP}$ dissolution adds an additional layer of complexity to the toxicological mechanisms by which NM could induce biological injury and may also be relevant to the effects of silica, $\mathrm{ZnS}$, and $\mathrm{CdSe}$. $\mathrm{ZnO}$ dissolution is particularly relevant to pulmonary toxicity and the development of metal fume fever in welders. This occupational hazard is caused by the inhalation of $\mathrm{ZnO}$ or $\mathrm{MgO}$ in the welding fumes and is characterized by a sudden onset of fever with X-ray negative respiratory inflammation. ${ }^{23}$ The injury response is characterized by a significant increase in polymorphonuclear cells in the bronchoalveolar lavage fluid along with an increase in TNF-a, IL-1 and IL-8. A small particle size facilitates the rate of dissolution, with additional enhancement by acidic $\mathrm{pH}$ or the presence of biological components such as proteins in the dissolving medium. In this regard, we have observed that the $\mathrm{ZnO}$ agglomerates shrink from 413 to $36 \mathrm{~nm}$ when transferred from water to tissue culture medium (Table 1). This could reflect the effect of serum components on particle dispersion or dissolution. Serum proteins and lipids have been shown to improve NP dispersion ${ }^{38}$ and may also assist in dissolution as suggested by the data in Fig. 2C. This size reduction of $\mathrm{ZnO}$ NP could facilitate cellular uptake and intracellular dissolution, particularly in the size-limited endosomal compartments. This 
could constitute a new nano-bio interface where acidification in the endosome or the presence of organic acids could speed up the rate of dissolution. This provides an alternative explanation for why no labeled particles could be seen in the lysosomal compartment of RAW 264.7 cells while fluorescent particles could be observed in a less acidic caveolar compartment in BEAS-2B cells. It is important to mention that particle dissolution does have a potential upside in that it decreases the duration of the tissue exposure and could explain why the symptoms of metal fume fever dissipate within 24-48 hours without any structural lung damage. ${ }^{23,26,27}$

From a physiological perspective, very little free $\mathrm{Zn}^{2+}$ is present in the cytosol of healthy cells. This divalent cation is mostly bound to proteins such as metallothioneins or sequestered in organelles such as lysosomes and mitochondria. ${ }^{53}$ The $\mathrm{Zn}$ content of mammalian cells is tightly controlled by two integral membrane protein families, namely the Zrt/Irt-like proteins (ZIPs) and zinc transporters (ZnTs). ${ }^{54}$ The ZIPs facilitate zinc uptake to the cytosol, while the $\mathrm{ZnTs}$ promote $\mathrm{Zn}^{2+}$ removal from the cytosol, either by extruding the cation from the cell or sequestering it in cytoplasmic vesicles and organelles. In this regard, $\mathrm{ZnT} 2,3$, and 4 have been shown to co-localize with LAMP-1 in the lysosomal compartment, while $\mathrm{ZnT} 2$ over-expression leads to significant $\mathrm{Zn}^{2+}$ accumulation within mature lysosomes. ${ }^{54}$ This suggests that lysosomes play an important role in $\mathrm{Zn}$ homeostasis in the cell, which could explain the fluorescence overlap of the Newport Green with the LAMP-1 probe in RAW 264.7 cells (Fig. 9A).

Although a number of in vivo and in vitro studies have addressed the toxicity of $\mathrm{ZnO}$, the mechanism of toxicity in mammalian cells remains unclear. Ultrafine $\mathrm{ZnO}$ particles are capable of reaching the alveoli and inducing pulmonary inflammation and metal fume fever. $^{23,25}$ It is also known that $\mathrm{ZnO}$ particles are toxic to several cell types under tissue culture conditions. ${ }^{28,29} \mathrm{We}$ further demonstrate that this toxicity includes the production of pro-inflammatory mediators and cell death, which represent Tiers 2 and 3 in the hierarchical oxidative stress model. ${ }^{1} \mathrm{ZnO}$ dissolution raises the intracellular $\left[\mathrm{Zn}^{2+}\right]$ and is associated with high levels of ROS production. These oxygen radicals could originate at the particle surface as well as from biological substrates such as damaged mitochondria. By contrast, $\mathrm{CeO}_{2}$ do not generate cellular ROS although the material itself is capable of spontaneous $\mathrm{H}_{2} \mathrm{O}_{2}$ production (Fig. 3A). The mitochondrial contribution to $\mathrm{ZnO}$-induced ROS production is suggested by the ultrastructural changes in this organelle (Figs. 4, 5, S5, S6), the increase in MitoSOX fluorescence and change in the membrane potential. Several studies in isolated mitochondria have shown that $\mathrm{Zn}^{2+}$ inhibits cellular respiration by interfering in cytochrome bc1 in complex III as well as with a-ketoglutarate dehydrogenase in complex I. ${ }^{52,53,55}$ It is also possible that $\mathrm{Zn}^{2+}$ may exert extra-mitochondrial effects contributing to ROS generation, including activation of NADPH oxidase via protein kinase $\mathrm{C}$ as well as NO production and generation of peroxynitrite $\left(\mathrm{ONOO}^{-}\right)$via the induction of nitric oxide synthase activity. ${ }^{52,53}$ Not only does $\mathrm{Zn}^{2+}$ trigger ROS generation but cellular oxidant injury could promote further $\mathrm{Zn}^{2+}$ release, e.g. from metallothioneins. ${ }^{52,53} \mathrm{Zinc}$ could also inhibit key enzymes in the glycolytic pathway, leading to ATP depletion in cells. ${ }^{56,57}$ Finally, high levels of $\mathrm{Zn}^{2+}$ could contribute directly to mitochondrial PT pore opening and cytochrome c release, resulting in apoptosis/necrosis in target cells. ${ }^{58,59}$

An unexpected finding in this study was that $\mathrm{CeO}_{2}$ could induce a protective cellular response in spite of the ability of these NP to generate ROS abiotically (Figs. 4, 5). This observation is compatible with the previous demonstration that this material could prevent increased cellular ROS generation in tissue culture cells. ${ }^{30}$ This was demonstrated by showing that prior incubation of RAW 264.7 and BEAS-2B cells with $\mathrm{CeO}_{2}$ could protect against the cytotoxic effects of a redox cycling organic DEP extract (Fig. 6). This finding may explain the previous demonstration of cytoprotective $\mathrm{CeO}_{2}$ effects. ${ }^{30-32}$ Intrinsic 
material properties could contribute to the antioxidants effects, including the mixed valence state of $\mathrm{CeO}_{2}\left(\mathrm{Ce}^{3+}\right.$ and $\left.\mathrm{Ce}^{4+}\right)$, allowing this material to act as a free radical scavenger. ${ }^{32}$ Moreover, the electron defects in nano-ceria are relatively resistant to the radical damage, thereby allowing an autoregenerative reaction cycle $\left(\mathrm{Ce}^{3+} \rightarrow \mathrm{Ce}^{4+} \rightarrow \mathrm{Ce}^{3+}\right)$ that perpetuates the scavenging activity ${ }^{60}$ Finally, it has also been demonstrated that $\mathrm{CeO}_{2}$ is capable of mimicking superoxide dismutase (SOD) activity with a catalytic rate constant that exceeds that of the biological enzyme. ${ }^{61}$

In summary, our data show differential toxic effects of metal oxide NP of roughly the same size. The route of cellular uptake as well as the material characteristics that lead to engagement of oxidative stress pathways determines the toxicological outcome. Although both $\mathrm{ZnO}$ and $\mathrm{CeO}_{2}$ particles could induce spontaneous $\mathrm{ROS}$ production, the former induced an injurious while the latter induced a protective response. These data confirm the utility of our tiered oxidative stress screening paradigm that can be adapted to test for paradigms of toxicity that do not directly relate to material oxidant activity. This is likely due to the fact that cellular responses such as inflammation, mitochondrial damage, lysosomal damage, $\left[\mathrm{Ca}^{2+}\right]_{\mathrm{i}}$ flux and cytoxicity also act as injury response pathways to insults other than oxidative stress We are currently using and upgrading this system to develop highthroughput screening methods to study NM toxicity.

\section{Conclusion}

The physicochemical and structural properties of NM affect their biological and toxicological effects. We demonstrate that dissolution plays an important role in $\mathrm{ZnO}$ induced cytotoxicity. $\mathrm{ZnO}$ dissociation disrupts cellular zinc homeostasis, leading to lysosomal and mitochondria damage and ultimately cell death. In contrast, the antioxidant properties of $\mathrm{CeO}_{2}$ protect cells from oxidant injury.

\section{Materials and Methods}

\section{Chemicals and Nanoparticles}

Propidium iodide (PI), fluorescein isothiocynate (FITC), succinic anhydride, and fluorescamine were purchased from Sigma (St. Louis, MO). 4',6-diamidino-2-phenylindole (DAPI), 5,5',6,6'-tetrachloro-1,1',3,3' tetraethylbenzimidazolylcarbocyanine iodide/chloride (JC-1), 1-amino-5-(2,7-dichloro-6-acetomethoxy-3-oxo-3H-xanthen-9-yl)phenoxy]-2-(2'amino-5'-methylphenoxy) ethane-N,N,N',N'-tetraacetic acid, pentaacetoxy-methyl ester (Fluo-4), Alexa 594-labeled secondary antibody, Dulbecco's Modified Eagle's medium (DMEM), penicillin/streptomycin, and L-glutamine were purchased from Invitrogen (Carlsbad, CA). The MTS assay kit was obtained from Promega (Madison, WI). Fetal calf serum (FCS) was from Atlanta Biologicals, Inc (Lawrenceville, GA). Rat anti-mouse monoclonal to lysosomal membrane glycoprotein 1 (LAMP-1, 1D4B) and mouse antihuman monoclonal (H4A3) were purchased from Abcam (Cambridge, MA). Rabbit anticaveolin-1 polyclonal antibody was purchased from BD Biosciences Pharmingen (San Jose, CA). De-ionized water was filtered through a $0.45 \mu \mathrm{m}$ pore polycarbonate syringe filter (Millipore, Billerica, MA). All chemicals were reagent grade and used without further purification or modification.

Synthesis of metal oxide NP by flame spray pyrolysis-The metal oxide NP were synthesized using a flame spray pyrolysis (FSP) reactor. ${ }^{62}$ A glass syringe supplied $3 \mathrm{ml} /$ min precursor solution into the oxygen-assisted atomizer nozzle. The precursor solution was dispersed into droplets by a $3.0 \mathrm{~L} / \mathrm{min}$ oxygen co-flow. The atomizer is surrounded by a ring of eighteen premixed (methane+oxygen) supporting flames placed at 6-mm radius from the center of the nozzle. The flow rate of the methane and oxygen supporting flames were 1.50 
and $1.50 \mathrm{~L} / \mathrm{min}$, respectively. The maximum flame temperature was estimated to be 2200$2600 \mathrm{~K} .{ }^{35}$ The particulate product was collected with the aid of a vacuum pump (Marathon electric type AQC) on two parallel $47 \mathrm{~mm}$ membrane filters (Cole Parmer, 1 micron PTFE). The particles were recovered from the filter by scraping without damaging the PTFE coating.

The precursor solvent was m-xylene (anhydrous, 99+\%, Aldrich, CAS Number 108-38-3) in all cases. All precursor solutions were prepared in a nitrogen environment to prevent hydrolysis by ambient humidity. The $\mathrm{TiO}_{2}$ precursor was prepared by mixing titanium (IV) isopropoxide (Aldrich, 97\%, CAS Number 546-68-9) with xylene to obtain a $0.5 \mathrm{M}$ metal solution. ${ }^{36,37}$ The $\mathrm{ZnO}$ precursor was prepared by mixing zinc naphthenate $<8 \%$ (Zn by wt) (Aldrich, CAS Number 12001-85-3) with xylene at appropriate ratios to achieve a $0.5 \mathrm{M}$ metal solution. ${ }^{63}$ The $\mathrm{CeO}_{2}$ precursor Ce (III) 2-ethylhexanoate, $49 \%$ in 2-ethylhexanoic acid (Alfa Aesar, Ce 12\% CAS Number 56797-01-4) was mixed with xylene to obtain a 0.2 $\mathrm{M}$ metal solution. ${ }^{64}$ Please notice that FSP is performed at such high temperatures that the final product is devoid of and toxic solvents.

\section{Physicochemical characterization}

All NPs were characterized for size, size distribution, shape, and charge. NP shape and structure was assessed by transmission electron microscopy (JEOL JEM 2010, JEOL USA, Inc., Peabody, MA). Microfilms were prepared by placing a drop of the respective NP suspension onto a 200-mesh copper TEM grid (Electron Microscopy Sciences, Washington, PA) and drying at room-temperature overnight. To obtain a representative view, a minimum of 5 images were collected for each sample. Particle size distribution (PSD) was assessed in a ZetaPALS (Brookhaven Instruments Corporation, Holtsville, NY) or ZetaSizer Nano (Malvern Instruments, Westborough, MA). The ZetaPALS measures the dynamic light scattering (DLS) in a suspension at $90^{\circ}$ angle and is capable of detecting particles in the size range $2 \mathrm{~nm}-2 \mu \mathrm{m}$. D. ZetaSizer Nano measures DLS at $173^{\circ}$ (backscattering) in the range is $0.6-6 \mu \mathrm{m}$. The ZetaPALS or ZetaSizer Nano was also used to measure the electrophoretic mobility of the NP while suspended in solution. Electrophoretic mobility is used as an approximation of particle surface charge is transformed into zeta potential using the Helmholtz-Smoluchowski equation. Size measurements and electrophoretic mobility of NP were performed in a dilute aqueous NP suspension at pH 7.0 as well as in complete cell culture media at $\mathrm{pH} 7.4 .^{7}$

\section{Carbon nanotube (CNT)-NADH peroxidase (Npx)-bioelectrode}

We used the CNT-Npx bioelectrode to quantify $\mathrm{H}_{2} \mathrm{O}_{2}$ generation by metal oxide NP. The apparatus is comprised of a Npx-bioassembly CNT array as the working electrode and an $\mathrm{Ag} / \mathrm{AgCl}$ reference electrode with a platinum wire as the counter electrode. ${ }^{7}$

Electrochemical measurements were performed on an Epsilon system (BASi) at $22^{\circ} \mathrm{C}$. The bioelectrodes were equilibrated in the reaction buffer (acetate buffer, $\mathrm{pH} 6$ ) or water, then scanned to obtain initial cyclic voltammograms (CV) of the enzyme assembly prior to sample measurements. Calibration curves were generated using standard $\mathrm{H}_{2} \mathrm{O}_{2}$ solutions at low $(<100 \mathrm{nM})$ and high $(100-4000 \mathrm{nM})$ concentration ranges. Samples of $\mathrm{TiO}_{2}, \mathrm{CeO}_{2}$, and $\mathrm{ZnO} N \mathrm{NP}$ were prepared through serial dilution in water to a final concentration of $10 \mu \mathrm{g} / \mathrm{ml}$. Scans were taken at $1 \mathrm{hr}$ at a scan rate of $100 \mathrm{mV} / \mathrm{sec}$. Between sample analyses, all samples were tightly sealed and stored in the dark at $4^{\circ} \mathrm{C}$. Prior to each measurement, the samples were slowly equilibrated to reach room temperature.

\section{Cell culture and co-incubation with NP}

All the NP solutions were prepared fresh from stock solutions $(10 \mathrm{mg} / \mathrm{ml})$ and sonicated in culture medium for $10 \mathrm{sec}$ before addition to the tissue culture plates. All cell cultures were 
maintained in $25 \mathrm{~cm}^{2}$ cell culture flasks, in which the cells were passaged at $70-80 \%$ confluency every 2-4 days. RAW 264.7 cells were cultured in Dulbecco's Modified Eagle Medium (DMEM) (Carlsbad, CA) containing 10\% FCS, $100 \mathrm{U} / \mathrm{ml}$ penicillin, $100 \mu \mathrm{g} / \mathrm{ml}$ streptomycin, and $2 \mathrm{mM} \mathrm{L}$-glutamine (complete medium). BEAS-2B cells were cultured in BEGM (San Diego, CA) in type I rat tail collagen-coated flasks or plates. To assess the cytoprotective effects of $\mathrm{CeO}_{2}$, cells were pre-incubated with the particles for 24 hours at 25 $\mu \mathrm{g} / \mathrm{ml}$, prior to the addition of $25 \mu \mathrm{g} / \mathrm{ml}$ of a well-characterized diesel exhaust particle (DEP) extract for 16 hours ${ }^{8}$. This extract has been previously determined to deliver a toxic insult due to the presence of redox cycling organic chemicals. ${ }^{65}$

\section{MTS cell viability assay}

Cellular viability was determined by the MTS assay, which looks at the reduction of (3-(4,5dimethylthiazol-2-yl)-5-(3-carboxymethoxyphenyl)-2-(4-sulfophenyl)-2H-tetrazolium (MTS) to formazan in viable cells. ${ }^{40}$ Briefly, $25 \times 10^{3}$ cells were plated onto 96 multi-well plates (Costar; Corning, NY). After incubation with the indicated doses of NP for various lengths of time at $37^{\circ} \mathrm{C}$, formazan absorbance was measured at $490 \mathrm{~nm}$. The amount of colored product formed was proportional to the number of live cells in culture. Mean absorbance of non-exposed cells served as the reference value for calculating $100 \%$ cellular viability.

RNA isolation-Total RNA was extracted from the cells by using the RNeasy Mini Kit (Qiagen Inc, Valencia, CA) according to the manufacturer's recommendations. Contaminating DNA was removed using a DNA-free kit (Ambion Inc, Austin, Tex). Total RNA was spectrophotometrically quantitated. A 1- $\mu \mathrm{g}$ RNA sample was reverse transcribed using the iScript cDNA Synthesis Kit (Bio-Rad Laboratories, Hercules, CA). The cDNA templates were stored at $-40^{\circ} \mathrm{C}$.

Real-time RT-PCR-PCR was performed with an iQ SYBR Green Supermix (Bio-Rad Laboratories) using an iCycler (Bio-Rad Laboratories) according to the manufacturer's instructions. The primers for mouse $\beta$-actin and human $\beta_{2}$-microglobulin, mouse and human HO-1, NQO-1, and Nrf2 were designed according to the Primer3 website (http://wwwgenome.wi.mit.edu/cgi-bin/primer/primer3_www.cgi). The mouse sequences for the primers are: (1) $\beta$-actin forward: AGCCATGTACGTAGCCATCC and reverse:

CTCTCAGCTGTGGTGGTGAA; (2) HO-1 forward: CACGCATATACCCGCTACCT and reverse: CCAGAGTGTTCATTCGAGCA; (3) NQO-1 forward: TTCTCTGGCCGATTCAGAGT and reverse: GGCTGCTTGGAGCAAAATAG; (4) Nrf2 forward: CTCGCTGGAAAAAGAAGTGG and reverse: CCGTCCAGGAGTTCAGAGAG. The human sequences for the primers are: (1) $\beta_{2}$-microglobulin forward:

ACTGAATTCACCCCCACTGA and reverse: CCTCCATGATGCTGCTTACA; (2) HO-1 forward: TCCGATGGGTCCTTACACTC and reverse: TAAGGAAGCCAGCCAAGAA; (3) NQO-1 forward: TTCTCTGGCCGATTCAGAGT and reverse: GGCTGCTTGGAGCAAAATAG; (4) Nrf2 forward: GCGACGGAAAGAGTATGAC and reverse: GTTGGCAGATCCACTGGTTT. The final PCR mixture contained $1 \mu \mathrm{L}$ cDNA template and $400 \mathrm{nmol} / \mathrm{L}$ of the forward and reverse primers in a final volume of $20 \mu \mathrm{L}$. Samples were run concurrently with a standard curve prepared from the PCR products. PCR conditions were three 3 -min steps of $94^{\circ} \mathrm{C}$ and 40 cycles of $94^{\circ} \mathrm{C}$ for $15 \mathrm{sec}, 60^{\circ} \mathrm{C}$ for $30 \mathrm{sec}$, and $72^{\circ} \mathrm{C}$ for $30 \mathrm{sec}$. Melting curve analysis was used to confirm specific replicon formation. Expression levels were determined from cycle thresholds using a standard curve, normalized to human $\beta_{2}$-microglobulin or mouse $\beta$-actin expression levels and expressed as fold. 


\section{Inductively-Coupled Plasma - Mass Spectrometer (ICP-MS) Analysis of Dissolved Zinc Concentrations in Cell Culture Media}

All analyses were done on a Perkin-Elmer SCIEX Elan DRCII ICP-MS. Samples were diluted 1:20 (gravimetrically) in $2 \%$ ultra high purity $\mathrm{HNO}_{3}$ and spiked with $\mathrm{Ga}$ as an internal standard. Ammonium $\left(\mathrm{NH}_{3}\right)$ was used as a reaction gas. The zinc concentration was determined from the $\mathrm{Zn}$ isotope with a mass:charge ratio $(\mathrm{m} / \mathrm{z})$ of 66 ; the values were monitored at $\mathrm{m} / \mathrm{z} 68$ and with $\mathrm{Ga}$ as internal standard at $\mathrm{m} / \mathrm{z} 69$. Selected samples were spiked with a Zn standard for which recoveries were within $90-110 \%$ and better. A preliminary study tested the ability of the ICP-MS instrument to accurately detect dissolved $\mathrm{Zn}$ in cell culture media. These solutions were found to be higher viscosity than water, affecting the flow rate to the instrument and the total $\mathrm{Zn}$ signal. However, this effect was corrected for by using an internal standard. It is presently estimated that this approach yields $\mathrm{Zn}$ concentration measurements in the $1-500 \mathrm{uM}$ range that is accurate to better than 5\%.

\section{Maximum Zinc lon Concentrations due to ZnO Dissolution in Cell Culture} Media-We estimated the equilibrium zinc concentrations in water, BEGM and DMEM by dissolving excess commercial $\mathrm{ZnO}$ nanopowder (Sigma $<100 \mathrm{~nm}$ ) in $25 \mathrm{~mL}$ volumes of these aqueous media for four days at room temperature with shaking. $1.5 \mathrm{~mL}$ aliquots were centrifuged for one hour with cooling, then $0.1 \mathrm{~mL}$ of supernatant was added to $0.9 \mathrm{~mL}$ of water and the resulting zinc solution measured by ICP-MS as described above.

\section{Tests of the Separation of ZnO Nanoparticles from Cell Culture Media using Centrifugation}

We added $\mathrm{ZnO}$ nanoparticles to $25 \mathrm{~mL}$ of BEGM and DMEM media at a concentration in excess of the maximum dissolved zinc concentrations measured as described above. The solutions were stirred for two hours, and six $1.5 \mathrm{~mL}$ aliquots were removed for tests of solid $\mathrm{ZnO}$ separation as a function of centrifugation time in a in a Beckman Coulter Allegra $\mathrm{X}-22 \mathrm{R}$ centrifuge with cooling. As shown in Fig S2, centrifugation at $22,000 \times \mathrm{g}$ for 5 minutes successfully removes solid phase $\mathrm{ZnO}$ from $\mathrm{BEGM}$, but is unable to remove all the excess $\mathrm{ZnO}$ in DMEM solutions.

Assessment of the kinetics of ZnO Nanoparticle Dissolution-Stock solutions were made of commercial 100-nm $\mathrm{ZnO}$ particles and of $\mathrm{ZnO}$ nanoparticles synthesized by Dr. Lutz Mädler (University of Bremen, Germany and CNSI, USA) at a concentration of 10 $\mathrm{mg} / \mathrm{mL}$. Experiments to measure the $\mathrm{ZnO}$ dissolution rate in water, high ionic strength solution, and cell culture media were performed as follows. Glass bottles containing $50 \mathrm{ml}$ of solution (one part of water and three parts of solution samples) were allowed to equilibrate to room temperature overnight $\left(22.2^{\circ} \mathrm{C}\right)$ with moderate stirring. Each liquid was sampled once, and then $50 \mathrm{uL}$ of a stock $\mathrm{ZnO}$ suspension was added to each. The stock suspension was thoroughly mixed by sonication for one minute initially, then by vortexing for 30 seconds before taking material to spike each sample. The $\mathrm{ZnO}$ addition procedure took approximately 2 minutes to complete from the first addition to the water sample. Each liquid was sampled by extracting $1.5 \mathrm{~mL}$ into a plastic vial, then all four samples were centrifuged for $5 \frac{1}{2}$ minutes at $20,000 \times \mathrm{g}$ in an Eppendorf tube. The vials were carefully removed and $1 \mathrm{~mL}$ of supernatant was transferred to a fresh vial for ICP-MS analysis. No visible sediment was observed at any stage.

\section{Cellular staining with fluorescent probes and flow cytometry}

Fluorescent probes were diluted in DMEM before the addition to cells for 15-30 min at 37 ${ }^{\circ} \mathrm{C}$ in the dark: (i) $47.5 \mu \mathrm{g} / \mathrm{ml}$ propidium iodide (PI) in $200 \mu \mathrm{l}$ DMEM (assessment of cell death); (ii) $5 \mu \mathrm{M} \mathrm{JC}-1$ (assessment of $\Delta \Psi \mathrm{m}$ ); (iii) $5 \mu \mathrm{M}$ Fluo-3 (assessment of cytoplasmic free calcium); and (iv) $5 \mu \mathrm{M}$ Newport Green DCF (assessment of cellular zinc). Flow 
cytometry was performed using a FACScan or LSR (Becton Dickinson, Mountain View, CA) equipped with a single $488 \mathrm{~nm}$ argon laser. Fluo-3 and Newport Green DCF

fluorescence was analyzed in the FL-1 channel, while PI was analyzed in FL-2; JC-1 was analyzed in both FL-1 and FL-2. Forward and side scatter were used to gate out cellular fragments. ${ }^{46,66}$

\section{Determination of TNF- $\alpha$ and IL-8 levels}

TNF- $a$ and IL-8 levels after particle treatments were measured by ELISA, as previously described. ${ }^{39,65}$

\section{Transmission electron microscopy of cells}

Harvested cells were fixed with $2.5 \%$ glutaraldehyde in $0.1 \mathrm{M}$ phosphate buffer (PBS) and washed. After post-fixation in $1 \% \mathrm{OsO}_{4}$ in PBS for $1 \mathrm{hr}$, the cells were dehydrated in a graded series of ethanol, treated with propylene oxide and embedded in Epon.

Approximated 60-70 nm thick sections were cut on a Reichert-Jung Ultracut E ultramicrotome and transferred to formvar-coated copper grids. The sections were stained with uranyl acetate and Reynolds lead citrate and examined on a JEOL 100CX electron microscope at $80 \mathrm{kV}$ in UCLA BRI Electron Microscopy Core.

\section{Fluorescent labeling of metal oxides}

The metal oxide particle surfaces were functionalized by the addition of primary amines, using aminopropyltriethoxysilane (APTS) to attach alkoxy silane groups to the surface hydroxiles. These amines are available for the attachment of fluorescein isothiocyanate (FITC) molecules. Four $\mathrm{mg}$ of the metal-oxide nanoparticles were dispersed in $3 \mathrm{~mL}$ anhydrous dimethylformamide (DMF). A solution of $0.5 \mu \mathrm{L}$ APTS diluted in $25 \mu \mathrm{L}$ DMF was added to the particle suspensions, sonicated and stirred under nitrogen at room temperature for 20 hours. The modified NP were collected by centrifuging and removing the supernatant. After washing, the modified NP were resuspended in $0.5 \mathrm{~mL}$ DMF and mixed with a solution of $1 \mathrm{mg}$ FITC and $0.5 \mathrm{~mL}$ DMF. The suspension was stirred for 4 hours and the FITC-labeled NP were collected by centrifugation. After thoroughly washing of the labeled materials with DMF, the particles were dried under vacuum to remove the organic solvent and stored as dry powders.

\section{Immunocytochemistry and confocal microscopy}

Cultured cells on chamber slides were fixed, permeabilized, and labeled with a standard immunocytochemistry protocol. ${ }^{40}$ LAMP-1 staining was performed by using a 1:500 dilution of a rat anti-mouse (1D4B) or mouse anti-human monoclonal antibody (H4A3), followed by an Alexa 594-labeled secondary antibody. Caveolin-1 was labeled with a primary rabbit anti-caveolin polyclonal antibody for $1 \mathrm{hr}$ at room temperature, followed by the addition of a 1:500 dilution of secondary Alexa-594-conjugated goat anti-rabbit IgG for $1 \mathrm{hr}$ at room temperature. Slides were counterstained with DAPI in PBS and visualized under a confocal microscope (Leica Confocal 1P/FCS). Confocal images were obtained with a $63 \times$ objective. Optical sections were averaged 2-4 times to reduce noise. Images were processed using Leica Confocal Software. Co-localization of labeled nanoparticles with LAMP-1 and caveolin-1 was quantified by the Image $\mathrm{J}$ from the NIH. ${ }^{40}$

\section{Supplementary Material}

Refer to Web version on PubMed Central for supplementary material. 


\section{Acknowledgments}

Funding for this study was provided by NSF-funded University of California Center for the Environmental Impact of Nanotechnology (UC CEIN), US Public Health Service Grants U19 AI070453, RO1 ES10553, and RO1 ES015498, as well as the U.S. EPA STAR award (RD-83241301) to the Southern California Particle Center. This work is also supported by the UC Lead Campus for Nanotoxicology Training and Research, funded by UC TSR\&TP. L.M. would like to thank the Deutsche Forschungsgemeinschaft DFG (German Research Foundation, Forschungsstipendium MA3333/1-1) for support and the department of Chemical and Biomolecular Engineering in University of California, Los Angeles, CA 90095 for hosting. Funding to JIY was provided by AFSOR (F49620-03-1-0365) and NIH (GM066466). Funding for JIZ was provided by NSF grant CHE0507929. Fluorescent microscopy was performed at the CNSI Advanced Light Microscopy/Spectroscopy Shared Facility at UCLA. BG acknowledges funding from DOE BES DE-AC02-05CH11231 and thanks Joern Larsen for the ICP-MS analyses performed in the Carl Steefel laboratory at LBNL. This work has not been subjected to the EPA for peer and policy review.

\section{References and Notes}

1. Nel A, Xia T, Mädler L, Li N. Toxic Potential of Materials at the Nanolevel. Science. 2006; 311:622-627. [PubMed: 16456071]

2. NRC. National Academies Press; Washington DC: 2007. Toxicity Testing in the 21st Century: A Vision and a Strategy. http://dels.nas.edu/dels/rpt_briefs/Toxicity_Testing_final.pdf

3. NRC. National Academies Press; Washington DC; 2006. Toxicity Testingfor Assessment of Environmental Agents: Interim Report. http://www.nae.edu/nae/naepcms.nsf/weblinks/ MKEZ-6JVLDY?OpenDocument

4. Donaldson K, Stone V, Borm PJ, Jimenez LA, Gilmour PS, Schins RP, Knaapen AM, Rahman I, Faux SP, Brown DM, et al. Oxidative Stress and Calcium Signaling in the Adverse Effects of Environmental Particles ( $\left.\mathrm{PM}_{10}\right)$. Free Radic Biol Med. 2003; 34:1369-1382. [PubMed: 12757847]

5. Nel A. Atmosphere. Air Pollution-Related Illness: Effects of Particles. Science. 2005; 308:804-806. [PubMed: 15879201]

6. Oberdorster G, Oberdorster E, Oberdorster J. Nanotoxicology: An Emerging Discipline Evolving from Studies of Ultrafine Particles. Environ Health Perspect. 2005; 113:823-839. [PubMed: 16002369]

7. Xia T, Kovochich M, Brant J, Hotze M, Sempf J, Oberley T, Sioutas C, Yeh JI, Wiesner MR, Nel AE. Comparison of the Abilities of Ambient and Manufactured Nanoparticles to Induce Cellular Toxicity according to an Oxidative Stress Paradigm. Nano Lett. 2006; 6:1794-1807. [PubMed: 16895376]

8. Xia T, Kovochich M, Nel A. The Role of Reactive Oxygen Species and Oxidative Stress in Mediating Particulate Matter Injury. Clin Occup Environ Med. 2006; 5:817-836. [PubMed: 17110294]

9. Colvin VL. The Potential Environmental Impact of Engineered Nanomaterials. Nat Biotechnol. 2003; 21:1166-1170. [PubMed: 14520401]

10. Donaldson K, Stone V, Tran CL, Kreyling W, Borm PJ. Nanotoxicology. Occup Environ Med. 2004; 61:727-728. [PubMed: 15317911]

11. Li N, Hao M, Phalen RF, Hinds WC, Nel AE. Particulate Air Pollutants and Asthma. A Paradigm for the Role of Oxidative Stress in PM-Induced Adverse Health Effects. Clin Immunol. 2003; 109:250-265. [PubMed: 14697739]

12. Xiao GG, Wang M, Li N, Loo JA, Nel AE. Use of Proteomics to Demonstrate a Hierarchical Oxidative Stress Response to Diesel Exhaust Particle Chemicals in a Macrophage Cell Line. J Biol Chem. 2003; 278:50781-50790. [PubMed: 14522998]

13. Araujo JA, Barajas B, Kleinman M, Wang X, Bennett BJ, Gong KW, Navab M, Harkema J, Sioutas C, Lusis AJ, et al. Ambient Particulate Pollutants in the Ultrafine Range Promote Early Atherosclerosis and Systemic Oxidative Stress. Circ Res. 2008; 102:589-596. [PubMed: 18202315]

14. Gong KW, Zhao W, Li N, Barajas B, Kleinman M, Sioutas C, Horvath S, Lusis AJ, Nel A, Araujo JA. Air-Pollutant Chemicals and Oxidized Lipids Exhibit Genome-wide Synergistic Effects on Endothelial Cells. Genome Biol. 2007; 8:R149. [PubMed: 17655762] 
15. Ayres JG, Borm P, Cassee FR, Castranova V, Donaldson K, Ghio A, Harrison RM, Hider R, Kelly F, Kooter IM, Marano F, Maynard RL, Mudway I, Nel A, Sioutas C, Smith S, Baeza-Squiban A, Cho A, Duggan S, Froines J. Evaluating the Toxicity of Airborne Particulate Matter and Nanoparticles by Measuring Oxidative Stress Potential--A Workshop Report and Consensus Statement. Inhal Toxicol. 2008; 20:75-99. [PubMed: 18236225]

16. Cedervall T, Lynch I, Lindman S, Berggard T, Thulin E, Nilsson H, Dawson KA, Linse S. Understanding the Nanoparticle-Protein Corona Using Methods to Quantify Exchange Rates and Affinities of Proteins for Nanoparticles. Proc Natl Acad Sci U S A. 2007; 104:2050-2055. [PubMed: 17267609]

17. Chen M, von MA. Formation of Nucleoplasmic Protein Aggregates Impairs Nuclear Function in Response to $\mathrm{SiO}_{2}$ Nanoparticles. Exp Cell Res. 2005; 305:51-62. [PubMed: 15777787]

18. Linse S, Cabaleiro-Lago C, Xue WF, Lynch I, Lindman S, Thulin E, Radford SE, Dawson KA. Nucleation of Protein Fibrillation by Nanoparticles. Proc Natl Acad Sci U S A. 2007; 104:86918696. [PubMed: 17485668]

19. Vertegel AA, Siegel RW, Dordick JS. Silica Nanoparticle Size Influences the Structure and Enzymatic Activity of Adsorbed Lysozyme. Langmuir. 2004; 20:6800-6807. [PubMed: 15274588]

20. Franklin NM, Rogers NJ, Apte SC, Batley GE, Gadd GE, Casey PS. Comparative Toxicity of Nanoparticulate $\mathrm{ZnO}$, bulk $\mathrm{ZnO}$, and $\mathrm{ZnCl}_{2}$ to a Freshwater Microalga (Pseudokirchneriella Subcapitata): the Importance of Particle Solubility. Environ Sci Technol. 2007; 41:8484-8490. [PubMed: 18200883]

21. ATSDR Toxicological Profile for Zinc. US Department of Health and Human Services, Public Health Service, Agency for Toxic Substances and Disease Registry. 2005

22. Moreau JW, Weber PK, Martin MC, Gilbert B, Hutcheon ID, Banfield JF. Extracellular Proteins Limit the Dispersal of Biogenic Nanoparticles. Science. 2007; 316:1600-1603. [PubMed: 17569859]

23. Brown JJ. Zinc Fume Fever. Br J Radiol. 1988; 61:327-329. [PubMed: 3370419]

24. Kuschner WG, D'Alessandro A, Wintermeyer SF, Wong H, Boushey HA, Blanc PD. Pulmonary Responses to Purified Zinc Oxide Fume. J Investig Med. 1995; 43:371-378.

25. Vogelmeier C, Konig G, Bencze K, Fruhmann G. Pulmonary Involvement in Zinc Fume Fever. Chest. 1987; 92:946-948. [PubMed: 3665618]

26. Martin CJ, Le XC, Guidotti TL, Yalcin S, Chum E, Audette RJ, Liang C, Yuan B, Zhang X, Wu J. Zinc Exposure in Chinese Foundry Workers. Am J Ind Med. 1999; 35:574-580. [PubMed: 10332510]

27. Rohrs LC. Metal-Fume Fever from Inhaling Zinc Oxide. AMA Arch Ind Health. 1957; 16:42-47. [PubMed: 13434495]

28. Gojova A, Guo B, Kota RS, Rutledge JC, Kennedy IM, Barakat AI. Induction of Inflammation in Vascular Endothelial Cells by Metal Oxide Nanoparticles: Effect of Particle Composition. Environ Health Perspect. 2007; 115:403-409. [PubMed: 17431490]

29. Jeng HA, Swanson J. Toxicity of Metal Oxide Nanoparticles in Mammalian Cells. J Environ Sci Health A Tox Hazard Subst Environ Eng. 2006; 41:2699-2711. [PubMed: 17114101]

30. Chen J, Patil S, Seal S, McGinnis JF. Rare Earth Nanoparticles Prevent Retinal Degeneration Induced by Intracellular Peroxides. Nat Nano. 2006; 1:142-150.

31. Schubert D, Dargusch R, Raitano J, Chan SW. Cerium and Yttrium Oxide Nanoparticles are Neuroprotective. Biochem Biophys Res Commun. 2006; 342:86-91. [PubMed: 16480682]

32. Tarnuzzer RW, Colon J, Patil S, Seal S. Vacancy Engineered Ceria Nanostructures for Protection from Radiation-Induced Cellular Damage. Nano Lett. 2005; 5:2573-2577. [PubMed: 16351218]

33. Mädler L. Liquid-fed Aerosol Reactors for One-Step Synthesis of Nanostructured Particles. KONA. 2004; 22:107-120.

34. Kammler HK, Mädler L, Pratsinis SE. Flame Synthesis of Nanoparticles. Chem Eng Technol. 2001; 24:583-596.

35. Mädler L, Kammler HK, Mueller R, Pratsinis SE. Controlled Synthesis of Nanostructured Particles by Flame Spray Pyrolysis. J Aerosol Sci. 2002; 33:369-389. 
36. Mädler L, Stark WJ, Pratsinis SE. Flame-Made Ceria Nanoparticles. J Mater Res. 2002; 17:13561362.

37. Mädler L, Stark WJ, Pratsinis SE. Rapid Synthesis of Stable ZnO Quantum Dots. J Appl Phys. 2002; 92:6537-6540.

38. Sager TM, Porter DW, Robinson VA, Lindsley WG, Schwegler-Berry D, Castranova V. Improved Method to Disperse Nanoparticles for in vitro and in vivo Investigation of Toxicity. Nanotoxicology. 2007; 1:118-129.

39. Li N, Wang M, Oberley TD, Sempf JM, Nel AE. Comparison of the Pro-Oxidative and Proinflammatory Effects of Organic Diesel Exhaust Particle Chemicals in Bronchial Epithelial Cells and Macrophages. J Immunol. 2002; 169:4531-4541. [PubMed: 12370390]

40. Xia T, Kovochich M, Liong M, Zink JI, Nel AE. Cationic Polystyrene Nanosphere Toxicity Depends on Cell-Specific Endocytic and Mitochondrial Injury Pathways. ACS Nano. 2008; 2:8596. [PubMed: 19206551]

41. Talalay P, Dinkova-Kostova AT, Holtzclaw WD. Importance of Phase 2 Gene Regulation in Protection Against Electrophile and Reactive Oxygen Toxicity and Carcinogenesis. Adv Enzyme Regul. 2003; 43:121-134. [PubMed: 12791387]

42. Li N, Alam J, Venkatesan MI, Eiguren-Fernandez A, Schmitz D, Di SE, Slaughter N, Killeen E, Wang X, Huang A, et al. Nrf2 Is a Key Transcription Factor that Regulates Antioxidant Defense in Macrophages and Epithelial Cells: Protecting Against the Proinflammatory and Oxidizing Effects of Diesel Exhaust Chemicals. J Immunol. 2004; 173:3467-3481. [PubMed: 15322212]

43. Wang M, Xiao GG, Li N, Xie Y, Loo JA, Nel AE. Use of a Fluorescent Phosphoprotein Dye to Characterize Oxidative Stress-induced Signaling Pathway Components in Macrophage and Epithelial Cultures Exposed to Diesel Exhaust Particle Chemicals. Electrophoresis. 2005; 26:2092-2108. [PubMed: 15880549]

44. Brookes PS, Yoon Y, Robotham JL, Anders MW, Sheu SS. Calcium, ATP, and ROS: A Mitochondrial Love-Hate Triangle. Am J Physiol Cell Physiol. 2004; 287:C817-C833. [PubMed: 15355853]

45. Jackson MJ, Papa S, Bolanos J, Bruckdorfer R, Carlsen H, Elliott RM, Flier J, Griffiths HR, Heales S, Holst B, et al. Antioxidants, Reactive Oxygen and Nitrogen Species, Gene Induction and Mitochondrial Function. Mol Aspects Med. 2002; 23:209-285. [PubMed: 12079772]

46. Li N, Venkatesan MI, Miguel A, Kaplan R, Gujuluva C, Alam J, Nel A. Induction of Heme Oxygenase-1 Expression in Macrophages by Diesel Exhaust Particle Chemicals and Quinones Via the Antioxidant-responsive Element. J Immunol. 2000; 165:3393-3401. [PubMed: 10975858]

47. Xia T, Korge P, Weiss JN, Li N, Venkatesen MI, Sioutas C, Nel A. Quinones and Aromatic Chemical Compounds in Particulate Matter Induce Mitochondrial Dysfunction: Implications for Ultrafine Particle Toxicity. Environ Health Perspect. 2004; 112:1347-1358. [PubMed: 15471724]

48. Foley S, Crowley C, Smaihi M, Bonfils C, Erlanger BF, Seta P, Larroque C. Cellular Localisation of a Water-Soluble Fullerene Derivative. Biochem Biophys Res Commun. 2002; 294:116-119. [PubMed: 12054749]

49. Li N, Sioutas C, Cho A, Schmitz D, Misra C, Sempf J, Wang M, Oberley T, Froines J, Nel A. Ultrafine Particulate Pollutants Induce Oxidative Stress and Mitochondrial Damage. Environ Health Perspect. 2003; 111:455-460. [PubMed: 12676598]

50. Grasset F, Saito N, Li D, Park D, Sakaguchi I, Ohashi N, Haneda H, Roisnel T, Mornet S, Duguet E. Surface Modification of Zinc Oxide Nanoparticles by Aminopropyltriethoxysilane. J Alloy Compd. 2003; 360:298-311.

51. Soares JW, Steeves DM, Ziegler D, DeCristofano BS. Surface Modification of Nanocrystalline Zinc Oxide for Bio-Sensing Applications. Proc SPIE. 2006; 6370:637011-1-637011-9.

52. Sensi SL, Yin HZ, Carriedo SG, Rao SS, Weiss JH. Preferential Zn2+ Influx Through $\mathrm{Ca}^{2+}$ permeable AMPA/kainate Channels Triggers Prolonged Mitochondrial Superoxide Production. Proc Natl Acad Sci U S A. 1999; 96:2414-2419. [PubMed: 10051656]

53. Frazzini V, Rockabrand E, Mocchegiani E, Sensi SL. Oxidative Stress and Brain Aging: Is Zinc the Link? Biogerontology. 2006; 7:307-314. [PubMed: 17028932] 
54. Falcon-Perez JM, Dell'Angelica EC. Zinc Transporter 2 (SLC30A2) Can Suppress the Vesicular Zinc Defect of Adaptor Protein 3-Depleted Fibroblasts by Promoting Zinc Accumulation in Lysosomes. Exp Cell Res. 2007; 313:1473-1483. [PubMed: 17349999]

55. Brown AM, Kristal BS, Effron MS, Shestopalov AI, Ullucci PA, Sheu KF, Blass JP, Cooper AJ. Zn2+ Inhibits Alpha-Ketoglutarate-Stimulated Mitochondrial Respiration and the Isolated AlphaKetoglutarate Dehydrogenase Complex. J Biol Chem. 2000; 275:13441-13447. [PubMed: 10788456]

56. Dineley KE, Votyakova TV, Reynolds IJ. Zinc Inhibition of Cellular Energy Production: Implications for Mitochondria and Neurodegeneration. J Neurochem. 2003; 85:563-570. [PubMed: 12694382]

57. Gazaryan IG, Krasinskaya IP, Kristal BS, Brown AM. Zinc Irreversibly Damages Major Enzymes of Energy Production and Antioxidant Defense Prior to Mitochondrial Permeability Transition. J Biol Chem. 2007; 282:24373-24380. [PubMed: 17565998]

58. Wudarczyk J, Debska G, Lenartowicz E. Zinc As an Inducer of the Membrane Permeability Transition in Rat Liver Mitochondria. Arch Biochem Biophys. 1999; 363(1):1-8. [PubMed: 10049493]

59. Jiang D, Sullivan PG, Sensi SL, Steward O, Weiss JH. Zn(2+) Induces Permeability Transition Pore Opening and Release of Pro-Apoptotic Peptides from Neuronal Mitochondria. J Biol Chem. 2001; 276:47524-47529. [PubMed: 11595748]

60. Das M, Patil S, Bhargava N, Kang JF, Riedel LM, Seal S, Hickman JJ. Auto-Catalytic Ceria Nanoparticles Offer Neuroprotection to Adult Rat Spinal Cord Neurons. Biomaterials. 2007; 28:1918-1925. [PubMed: 17222903]

61. Korsvik C, Patil S, Seal S, Self WT. Superoxide Dismutase Mimetic Properties Exhibited by Vacancy Engineered Ceria Nanoparticles. Chem Commun. 2007; 10:1056-1058.

62. Tani T, Mädler L, Pratsinis SE. Homogeneous ZnO Nanoparticles By Flame Spray Pyrolysis. J Nanopart Res. 2002; 4:337-343.

63. Height MJ, Mädler L, Pratsinis SE, Krumeich F. Nanorods of ZnO Made By Flame Spray pyrolysis. Chem Mater. 2006; 18:572-578.

64. Strobel R, Stark WJ, Mädler L, Pratsinis SE, Baiker A. Flame-Made Platinum/Alumina: Structural Properties and Catalytic Behaviour in Enantioselective Hydrogenation. J Catal. 2003; 213:296304.

65. Li N, Kim S, Wang M, Froines J, Sioutas C, Nel A. Use of A Stratified Oxidative Stress Model to Study the Biological Effects of Ambient Concentrated and Diesel Exhaust Particulate Matter. Inhal Toxicol. 2002; 14:459-486. [PubMed: 12028803]

66. Hiura TS, Li N, Kaplan R, Horwitz M, Seagrave JC, Nel AE. The Role of A Mitochondrial Pathway In the Induction of Apoptosis By Chemicals Extracted From Diesel Exhaust Particles. J Immunol. 2000; 165:2703-2711. [PubMed: 10946301] 

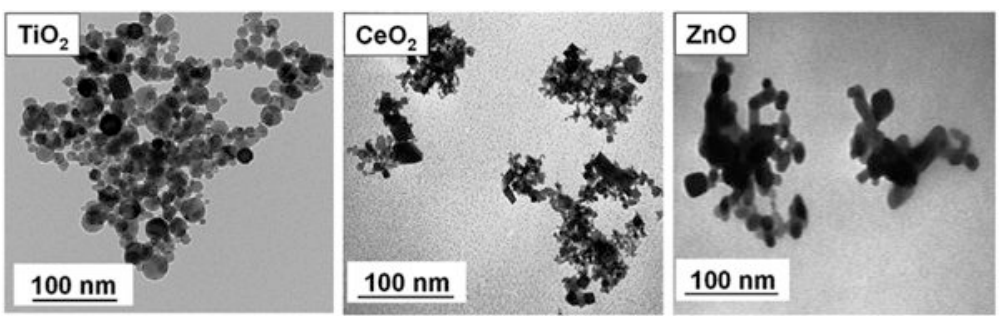

Fig. 1. TEM of the NPs used in this study

All NPs were prepared and applied to grids as described in the Materials and Methods. Pictures were taken with a JEOL 100CX electron microscope at $80 \mathrm{kV}$ and 190,000 $\times$ magnification. 

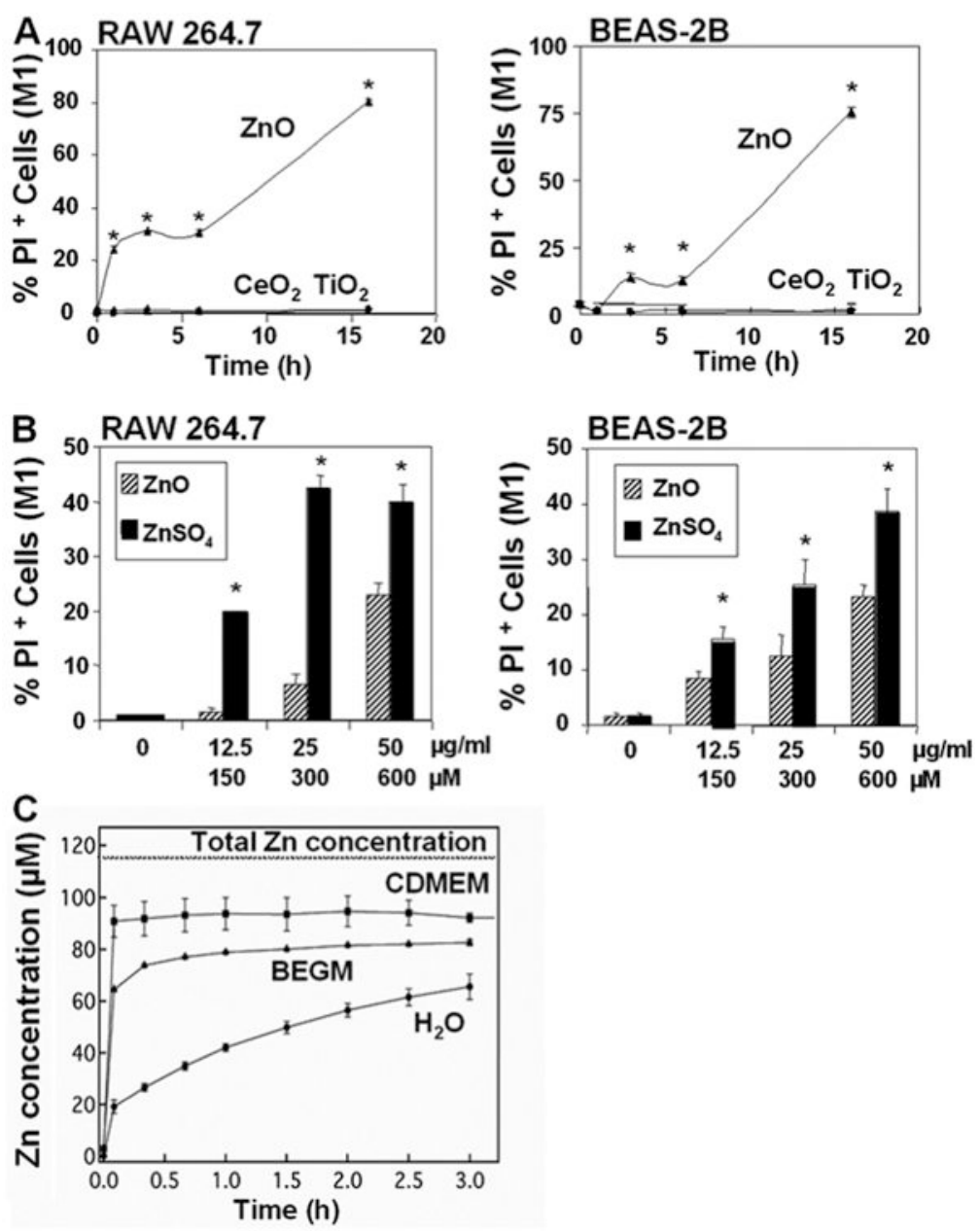

Fig. 2. Cell death detection by PI staining and the kinetics of $\mathrm{ZnO}$ dissolution in solution (A) After exposure to NPs suspended in tissue culture medium at $25 \mu \mathrm{g} / \mathrm{ml}$ for $1-16 \mathrm{hrs}$, cells were stained with $47.5 \mu \mathrm{g} / \mathrm{ml}$ PI and immediately analyzed in a LSR flow cytometer. The \% PI-positive (M1-gated) cells were scored by Cellquest. (B) PI uptake in response to exposure to $12.5-50 \mu \mathrm{g} / \mathrm{ml} \mathrm{ZnO}$ and an equimolar concentration of $\mathrm{Zn}$ in the form of a $\mathrm{ZnSO}_{4}$ solution for $6 \mathrm{hr}$. The maximum molar concentration of $\mathrm{Zn}$ added to these cultures in particulate or suspended form were 150,300 , and $600 \mu \mathrm{M}$, respectively. (C) The kinetics of $\mathrm{ZnO}$ nanoparticle dissolution in water and the two cell culture media: (i) complete DMEM containing $10 \%$ FBS and (ii) BEGM containing growth factors, cytokines, and supplements. Each data point is the average of three replicates, with error bars denoting the standard deviation. 

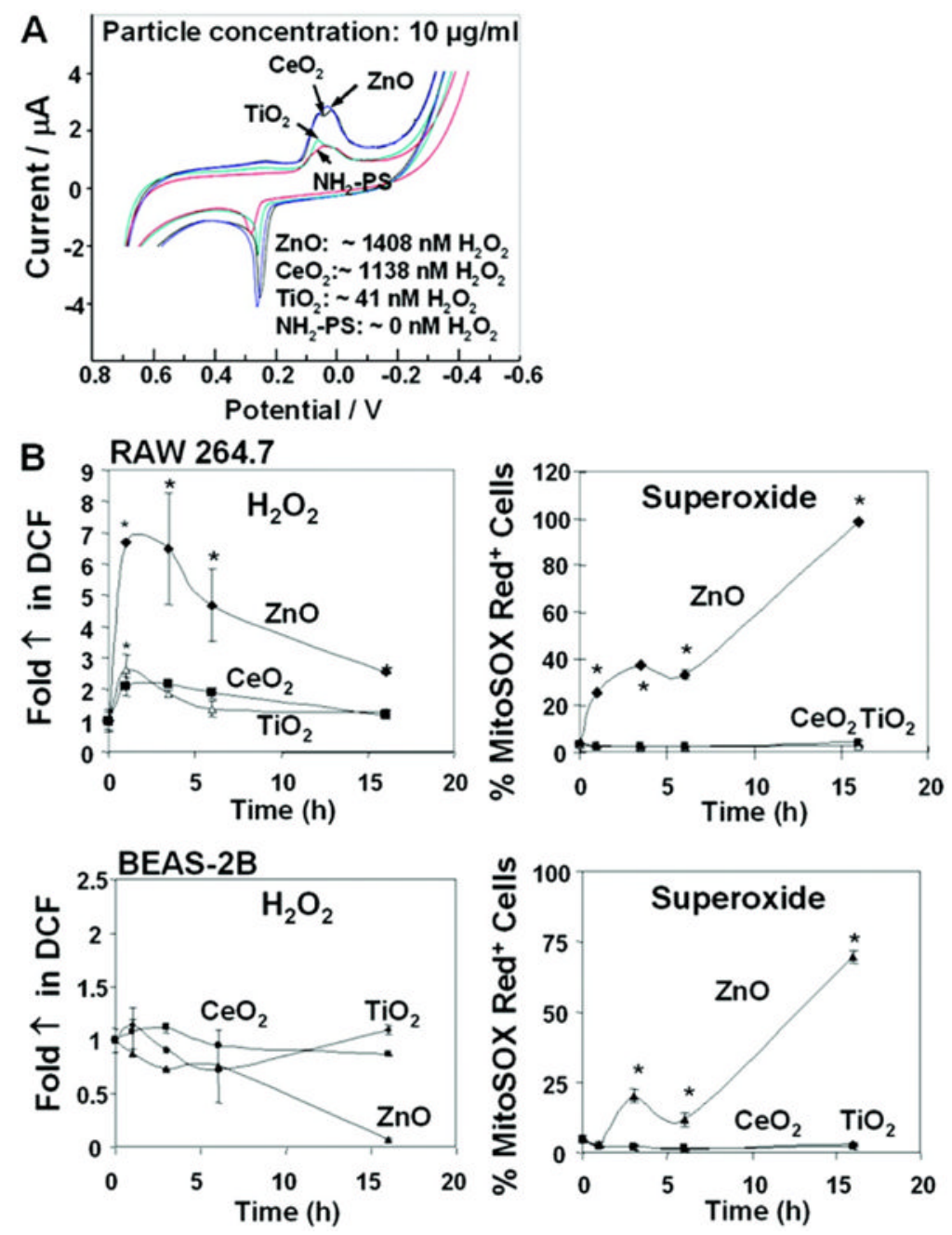

Fig. 3. Assessment of $\mathrm{H}_{2} \mathrm{O}_{2}$ generation under abiotic and biotic conditions

(A) Cyclic voltammograms of individual NP demonstrate a clear redox signal for $10 \mu \mathrm{g} / \mathrm{ml}$ $\mathrm{ZnO}, \mathrm{CeO}_{2}$, and $\mathrm{TiO}_{2}$ in a CNT-Npx-bioelectrode platform. The signal for amino-labeled $\mathrm{PS}$ is the same as for the medium background. The signal was quantified using calibration curves generated by $\mathrm{H}_{2} \mathrm{O}_{2}$ as described in Materials and Methods. ( $\mathrm{B}$ ) $\mathrm{H}_{2} \mathrm{O}_{2}$ and mitochondrial $\mathrm{O}_{2}{ }^{--}$production in RAW 264.7 and BEAS-2B cells were determined by the use of the intracellular dyes DCF and MitoSOX Red, respectively. Cells were incubated with $5 \mu \mathrm{M}$ dyes for $30 \mathrm{~min}$ and analyzed in a LSR flow cytometer. The data were reproduced once. 
A

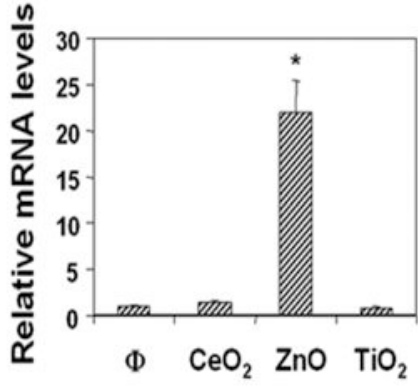

$B$
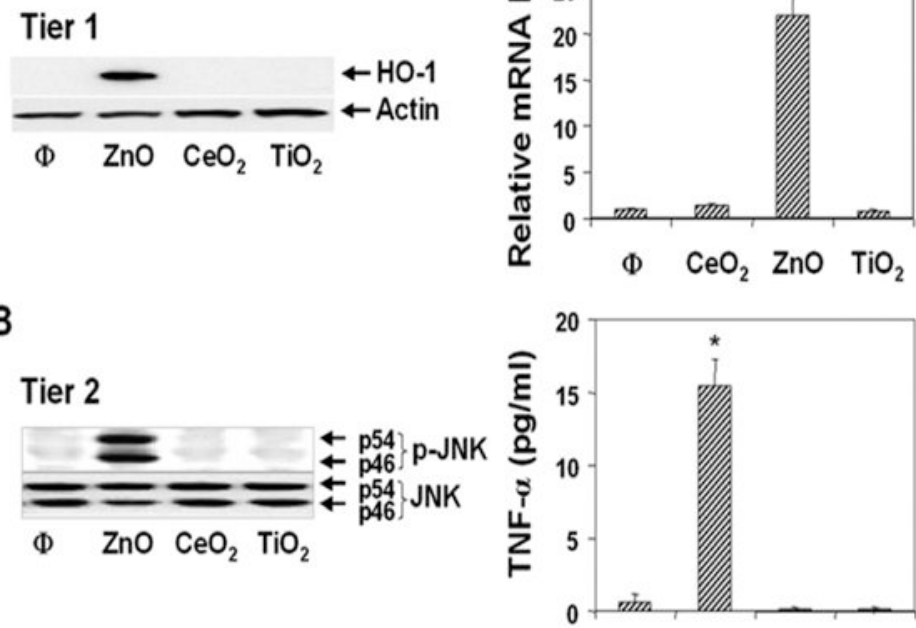

C Tier 3

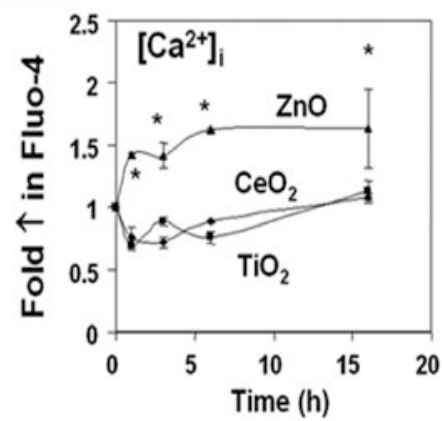

(1) $\mathrm{ZnO} \quad \mathrm{CeO}_{2} \mathrm{TiO}_{2}$

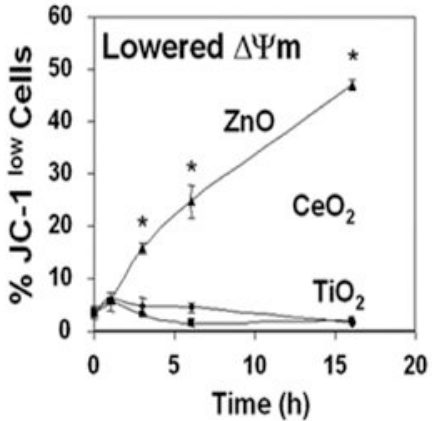

Fig. 4. Assessment of the three tiers of oxidative stress in RAW 274.7 cells

Cells were exposed to $25 \mu \mathrm{g} / \mathrm{ml}$ metal oxide NP for 1-16 hrs. The methodology for assessment of the hierarchical oxidative stress responses is described in Materials and Methods. (A) Induction of HO-1 expression (Tier 1) by immunoblotting and realtime PCR. (B) Jun kinase activation and TNF-a production in response to NPs (Tier 2). (C) Assessment of $\left[\mathrm{Ca}^{2+}\right]_{\mathrm{i}}$ and mitochondrial membrane potential $(\Delta \Psi \mathrm{m})$ (Tier 3) using Fluo-4 and JC-1 fluorescent dyes, respectively. Flow cytometry was performed 1 - 16 hrs after the addition of the particles. The increase in $\left[\mathrm{Ca}^{2+}\right]_{\mathrm{i}}$ can lead to cellular toxicity by triggering mitochondrial PT pore opening if the stories capacity of this organelle is exceeded. ${ }^{*} p<0.01$ compared with control. Data are representative of 3 separate experiments. 
A

Tier 1

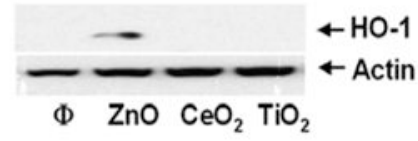

B

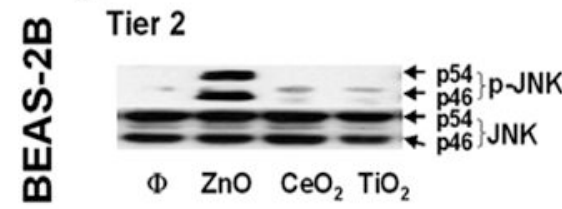

C Tier 3

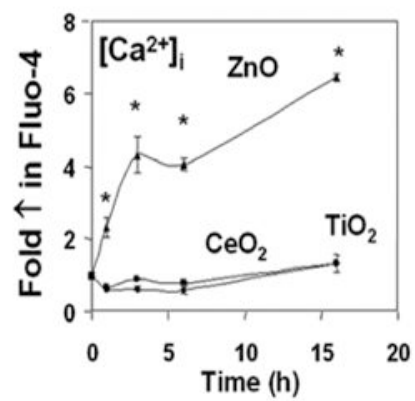

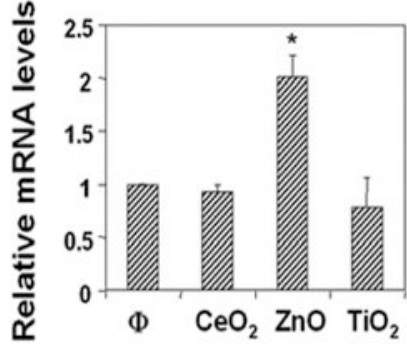

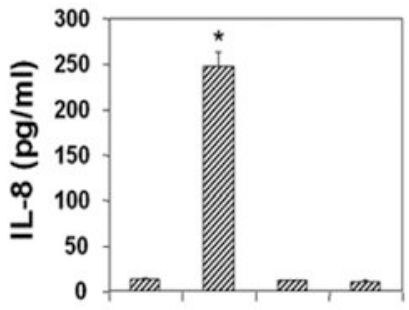

(1) $\mathrm{ZnO} \mathrm{CeO}_{2} \mathrm{TiO}_{2}$

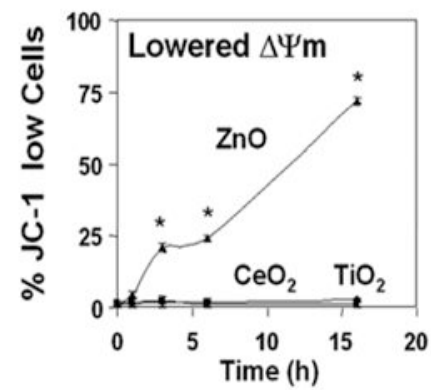

Fig. 5. Assessment of the three tiers of oxidative stress in BEAS-2B cells Cellular treatment and performance of the oxidative stress assays are similar to those described in Fig. 4. (A) Induction of HO-1 transcription and expression (Tier 1). (B) Jun kinase activation and IL-8 production (Tier 2). (C) Changes in mitochondrial membrane potential $(\Delta \Psi \mathrm{m})$ and intracellular free calcium $\left[\mathrm{Ca}^{2+}\right]_{\mathrm{i}}$ (Tier 3$) .{ }^{*} p<0.01$ compared with control. Data are representative of 3 separate experiments. 

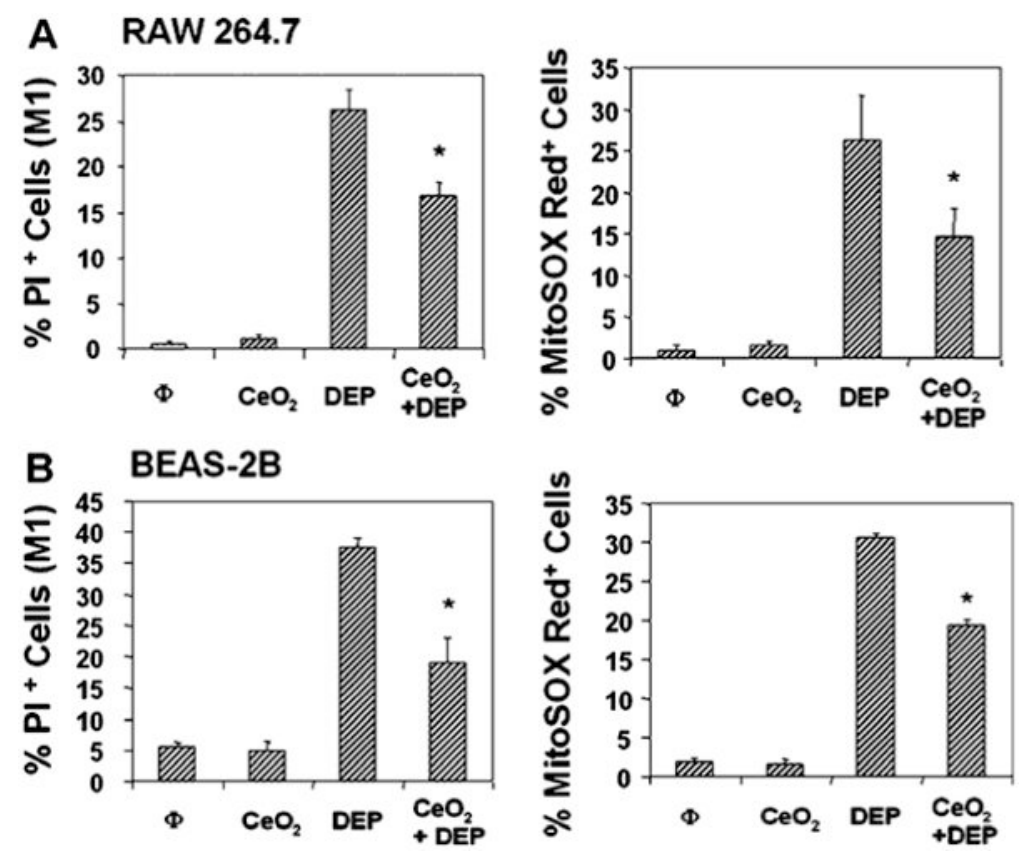

Fig. 6. Protective effect of $\mathrm{CeO}_{2}$ on DEP induced apoptosis

RAW 264.7 and BEAS-2B cells were pretreated with $25 \mu \mathrm{g} / \mathrm{ml} \mathrm{CeO}$ for $24 \mathrm{hr}$, followed by the addition of $25 \mu \mathrm{g} / \mathrm{ml}$ of an organic DEP extract for $16 \mathrm{hrs} .{ }^{31}$ The chemical composition and toxicity of this extract has been documented previously. Cell death was assessed by PI staining and superoxide levels determined by performance of MitoSOX red flow cytometry. ${ }^{*} p<0.01$ compared with DEP. Data are representative of three separate experiments. 


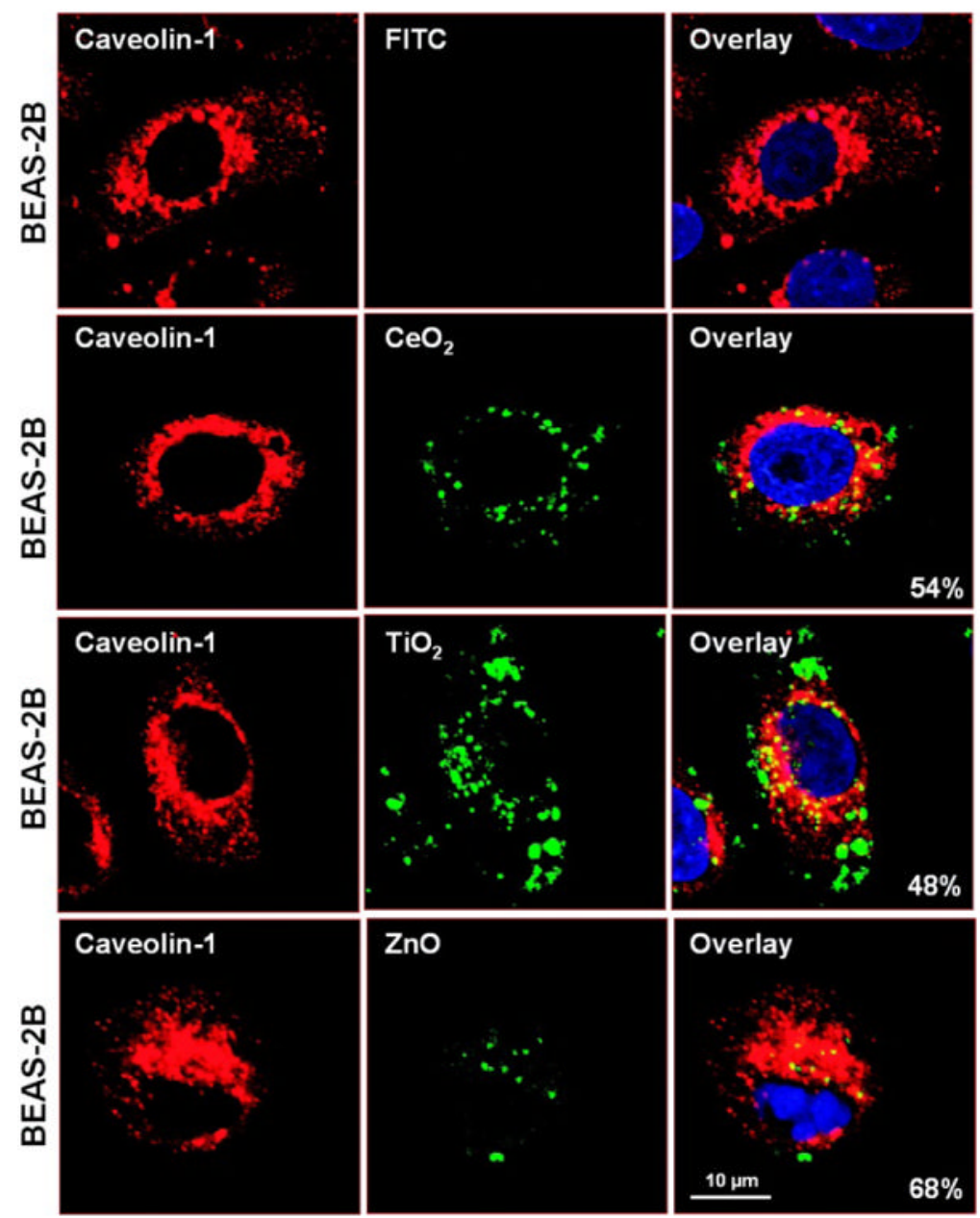

Fig. 7. Confocal microscopy to study the subcellular localization of FITC-labeled metal oxide NP in BEAS-2B cells

Cells were exposed to $25 \mu \mathrm{g} / \mathrm{ml}$ FITC-labeled particles for $6 \mathrm{hr}$. After fixation and permeabilization, cells were stained with $1 \mu \mathrm{g} / \mathrm{ml}$ anti-caveolin-1 (BD BioSciences, San Jose, CA) and visualized using a Confocal 1P/FCS Inverted microscope. After merging of the red and green images, the \% of cells with particles co-localizing with caveolae (composite yellow fluorescence) was quantified by Image J software. 


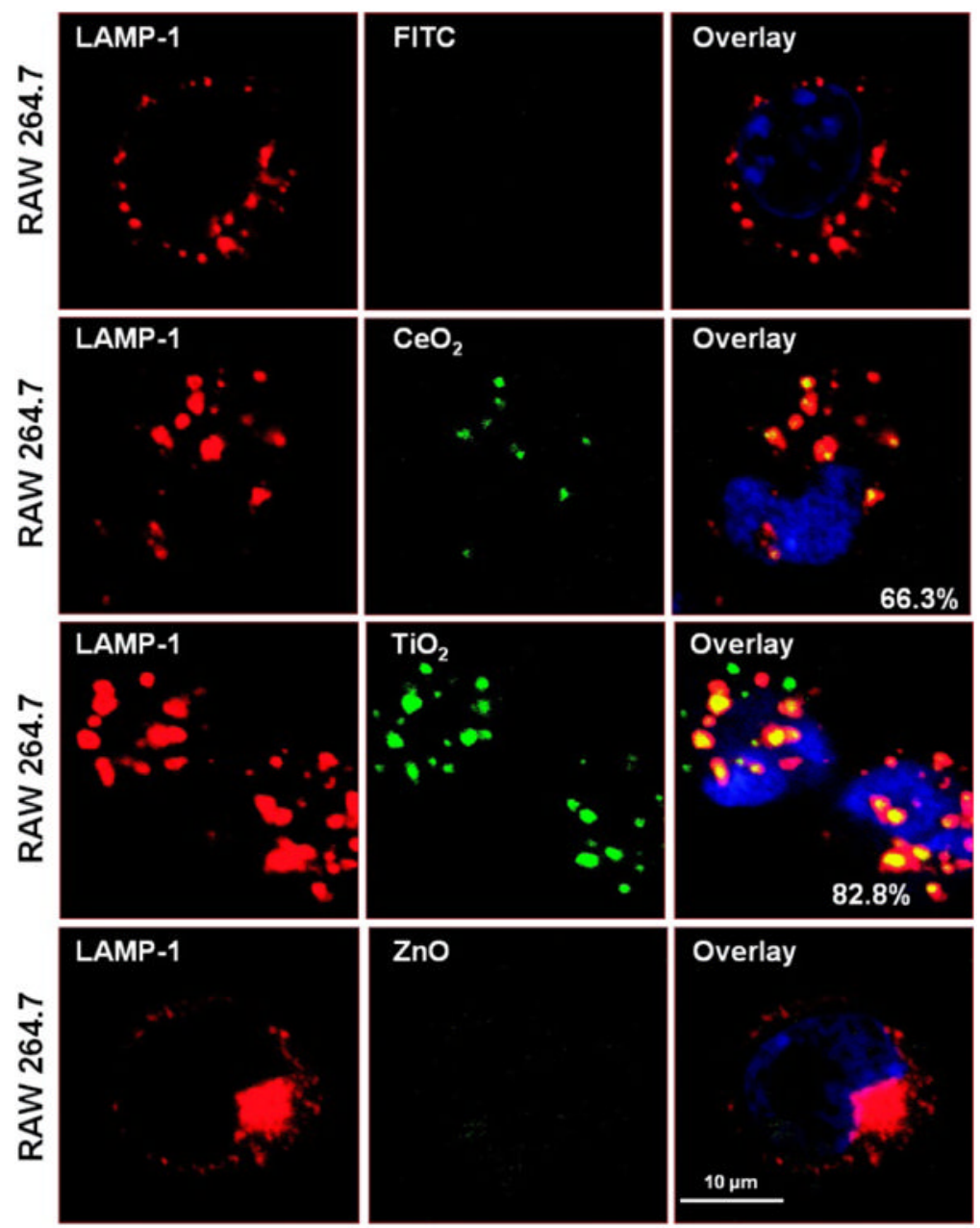

Fig. 8. Confocal microscopy to study the subcellular localization of FITC-labeled metal oxide NP in RAW 264.7 cells

Cells were exposed and processed as in Fig. 6, except that an Alexa 594 labeled antibody to the LAMP-1 was used to visualize lysosomes. After merging, the \% particles co-localizing with LAMP-1 (composite yellow fluorescence) was quantified by Image J software. 

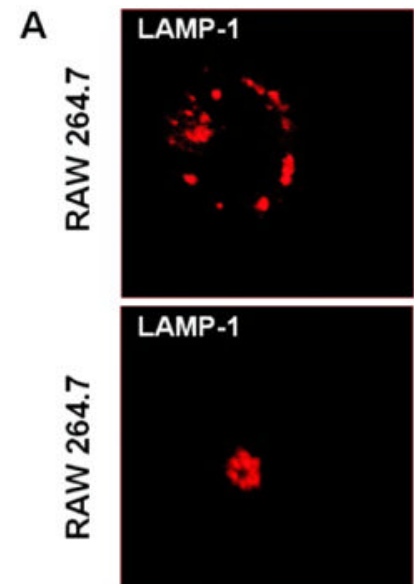

B
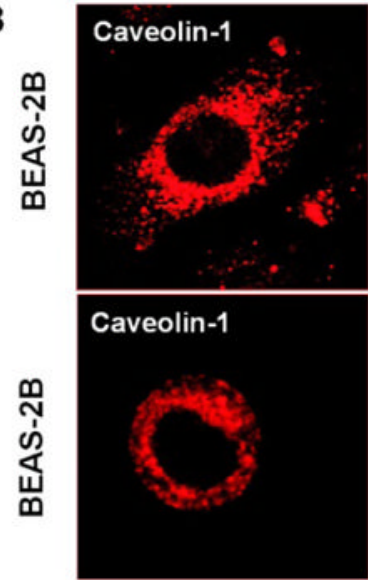
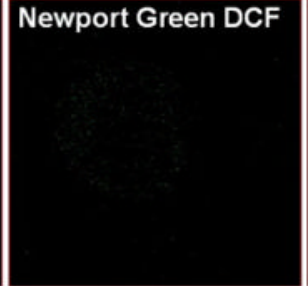

Newport Green DCF $\mathrm{ZnO}$
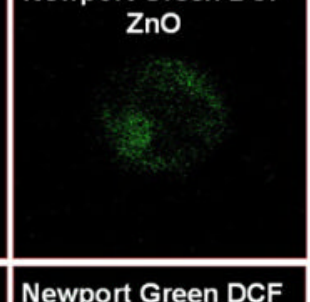

Newport Green DCF

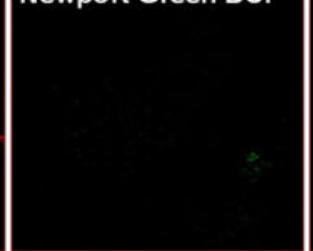

Newport Green DCF $\mathrm{ZnO}$

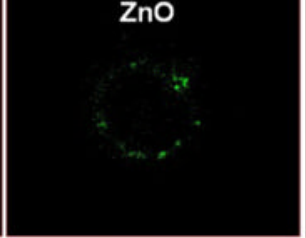

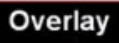

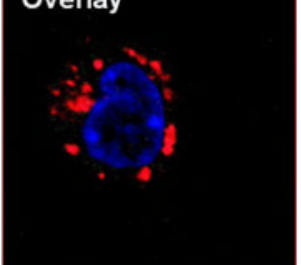

Overlay

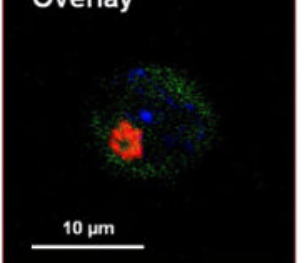

Overlay

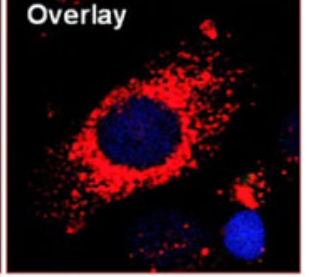

Overlay

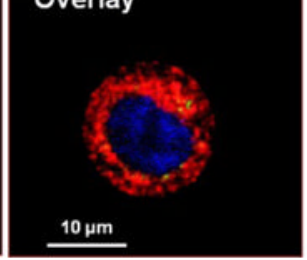

Fig. 9. Confocal microscopy to study the cellular distribution of $\mathrm{Zn}^{2+}$ in RAW 264.7 and BEAS-2B cells

(A) RAW 264.7 cells were exposed to $25 \mu \mathrm{g} / \mathrm{ml} \mathrm{ZnO} \mathrm{NP}$ for $6 \mathrm{hr}$. Cells were stained with 5 $\mu \mathrm{M}$ Newport Green DCF for $30 \mathrm{~min}$. After permeabilization and fixation, cells were stained with the lysosomal marker LAMP-1 and visualized in a confocal microscope. (B) BEAS-2B cells were treated with $25 \mu \mathrm{g} / \mathrm{ml} \mathrm{ZnO} \mathrm{NP}$ for $6 \mathrm{hr}$. Cells were similarly stained with Newport Green DCF as above. After fixation and permeabilization, cells were stained for the caveolar marker, caveolin-1, and visualized in a confocal microscope. 


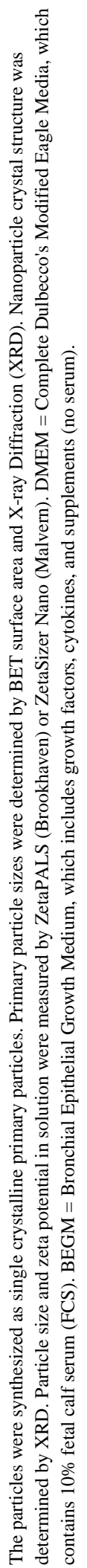

